\title{
The athletic gut microbiota
}

Alex E. Mohr ${ }^{{ }^{*}}$ (D), Ralf Jäger ${ }^{2}$, Katie C. Carpenter ${ }^{3}$, Chad M. Kerksick ${ }^{4}$, Martin Purpura ${ }^{2}$, Jeremy R. Townsend ${ }^{5}$, Nicholas P. West ${ }^{6}$, Katherine Black ${ }^{7}$, Michael Gleeson ${ }^{8}$, David B. Pyne ${ }^{9}$, Shawn D. Wells ${ }^{10}$, Shawn M. Arent ${ }^{11}$, Richard B. Kreider ${ }^{12}$, Bill I. Campbell ${ }^{13}$, Laurent Bannock ${ }^{14}$, Jonathan Scheiman ${ }^{15}$, Craig J. Wissent ${ }^{16}$, Marco Pane ${ }^{17}$, Douglas S. Kalman ${ }^{18}$, Jamie N. Pugh ${ }^{19}$, Carmen P. Ortega-Santos ${ }^{1}$, Jessica A. ter Haar ${ }^{20}$, Paul J. Arciero ${ }^{21}$ and Jose Antonio ${ }^{22}$

\begin{abstract}
The microorganisms in the gastrointestinal tract play a significant role in nutrient uptake, vitamin synthesis, energy harvest, inflammatory modulation, and host immune response, collectively contributing to human health. Important factors such as age, birth method, antibiotic use, and diet have been established as formative factors that shape the gut microbiota. Yet, less described is the role that exercise plays, particularly how associated factors and stressors, such as sport/exercise-specific diet, environment, and their interactions, may influence the gut microbiota. In particular, high-level athletes offer remarkable physiology and metabolism (including muscular strength/power, aerobic capacity, energy expenditure, and heat production) compared to sedentary individuals, and provide unique insight in gut microbiota research. In addition, the gut microbiota with its ability to harvest energy, modulate the immune system, and influence gastrointestinal health, likely plays an important role in athlete health, wellbeing, and sports performance. Therefore, understanding the mechanisms in which the gut microbiota could play in the role of influencing athletic performance is of considerable interest to athletes who work to improve their results in competition as well as reduce recovery time during training. Ultimately this research is expected to extend beyond athletics as understanding optimal fitness has applications for overall health and wellness in larger communities. Therefore, the purpose of this narrative review is to summarize current knowledge of the athletic gut microbiota and the factors that shape it. Exercise, associated dietary factors, and the athletic classification promote a more "health-associated" gut microbiota. Such features include a higher abundance of health-promoting bacterial species, increased microbial diversity, functional metabolic capacity, and microbial-associated metabolites, stimulation of bacterial abundance that can modulate mucosal immunity, and improved gastrointestinal barrier function.
\end{abstract}

Keywords: Athletes, Gut microbiome, Microbial ecology, Gut health, Sports nutrition, Sport performance, Exercise, Physical activity, Metagenome, Short-chain fatty acids

\section{Introduction}

The human gut microbiota contains thousands of different bacterial taxa as well as various archaea, eukaryotic microbes and viruses, more than three million genes, and harbors an enormous metabolic capacity $[1,2]$. The microorganisms in the gastrointestinal (GI) tract play a role in nutrient uptake, vitamin synthesis, energy

\footnotetext{
* Correspondence: aemohr@asu.edu

${ }^{1}$ College of Health Solutions, Arizona State University, Phoenix, AZ, USA

Full list of author information is available at the end of the article
}

harvest, inflammatory modulation, and host immune response [3, 4]. In turn, numerous intrinsic and extrinsic factors can affect the gut microbiota which results in a complex gut ecosystem that is highly dynamic and individual $[5,6]$. Important factors such as age, birth delivery route, antibiotic use, and diet can shape the gut microbiota [7-10]. The role that exercise plays, in particular the associated factors and stressors, such as sport/exercise-specific diet [11], environment [12], and their interactions, on the gut microbiota have been less well 
described. Athletes, although diverse as a population given the wide variety of different types of exercise/fitness/athletic training, competition, dietary practices and attributes, exemplify these factors on a generally consistent and long-term basis.

High-level athletes possess remarkable physiological and metabolic adaptations (including muscular strength/ power, aerobic capacity, energy expenditure, and heat production) and provide unique insight in gut microbiome research. In addition, the gut microbiota with its ability to harvest energy, modulate the immune system, and influence mucosal and brain health, is likely to play a significant role in athlete health, wellbeing, and sports performance [13-15]. The microbiota has an indirect influence on various indices of exercise performance, recovery, and patterns of illness, such as signaling through myokines and other cytokines, modulating activation of the hypothalamic-pituitary-adrenal axis, and affecting performance-associated metabolic pathways [13, 16-18]. Understanding the various roles the gut microbiota plays in relation to athletic performance is of great interest to athletes seeking to improve competition outcomes as well as reduce recovery time from training. Such knowledge may be of general benefit to further understanding of microbial contributions to human health and disease. Current research reports a higher abundance of healthpromoting bacterial species and increased microbial diversity in athletes $[13,18,19]$.

Given the increasing interest in exercise, associated dietary factors, and athletes as a population in relation to the gut microbiota, the purpose of this narrative review is to summarize current knowledge of the athletic gut microbiota and the factors that shape it. While differences likely exist among how the gut microbiota is affected by the different types of sport/athlete/fitness training regimens (e.g., resistance, interval, stretching/ flexibility, endurance/aerobic, etc.), the primary aim is to provide a "state-of-the-art research" statement. Key topics covered include:

- How the athletic/exercise-associated gut microbiota differs in comparison to other populations.

- The effects of different types of exercise training on the gut microbiota.

- The effects of an 'athletic diet' on the gut microbiota.

\section{Influencing factors that shape the gut microbiota}

Numerous factors such as age, genetics, drug use, stress, smoking, and diet can all affect the microbial composition of the gut, influencing a complex ecosystem that is highly dynamic and individual $[5-7,20]$. For example, the manner in which we are born and raised can result in substantial differences in the composition of the gut microbiota. This outcome is related to the differences in exposure (or non-exposure) of bacteria in the birth canal during vaginal birth [10], being bottle fed or breastfed [21], living with a dog, cat, or close to farm animals [22], the number of antibiotic treatments administered [8], and environmental toxin exposure [23]. From birth until the age of about 3 years, an individual assembles their core of resident microbiota primarily dominated by gram-positive Firmicutes and gram-negative Bacteroidetes phyla, and this subsequent make-up is as unique as a set of fingerprints [24-26]. The gut microbiota is also essential for processing dietary components and appears to have a major role in shaping the immune system [27]. Not surprisingly, the role of the gut microbiota in determining host health and development of disease has been gaining clinical and community interest [9]. Altered gut microbiota composition and/or function is linked to a growing number of conditions from metabolic disorders to some brain-related dysfunctions [28, 29]. Individuals in a known disease state can have a significantly different gut microbiota composition compared with healthy individuals [30]. A common observation is increased species diversity and/or richness in the gut microbiota of healthy individuals. Although new research suggests gene content/diversity in the gut may be a better predictor of physiological states [31]. In addition, counterexamples exist as recent work links high gut microbial diversity with a longer colonic transit time and systemic circulation of potentially harmful protein degradation products [32]. On a compositional level, it could be that low diversity indicates poorer health, while high diversity does not always guarantee improved health. Thus, information about compositional diversity alone is not sufficient to assess the health of the microbiota (and the host). Although, from an ecological perspective, functional diversity may be a key factor in allowing an ecosystem to continue operating properly [33]. Resilience to both external and internal changes (with the ability to rapidly return to its baseline functional profile) is likely a key feature of a healthy gut microbiota's ability to maintain itself [34].

In individuals without disease, "health-associated" microbiota is preferred to the term "healthy microbiota", since gut microbial composition alone cannot predict any state of health or disease according to currently available research [30,34]. It may turn out that many possible states of microbial composition are associated with health or indeed that a "health-associated" microbiota is more resilient and resistant to disruption [35]. It is also important to keep in consideration that gut microbiome composition is quite stable over time [36, 37]. For example, $\sim 60 \%$ of microbiome composition was found to be stable up to a 5-year period in US adults [38]. In addition, while species composition varies 
tremendously from person to person, there is substantial functional redundancy at the metabolic pathway level [1, $2,39]$. Therefore, looking at metagenomic functions rather than taxonomy alone may provide for a better appreciation of the true gut microbiome metabolic activity and the impact of microbial functions on human physiology [40, 41]. Physical activity has been an area of growing interest in gut microbiota research and appears to promote a health-associated microbial community and increased metabolic functional potential. This work includes identifying the impact that varying and diverse athletic and physical activity regimens exert on the gut microbiota.

Physical activity focused gut microbiota research is quite new and enabled by dramatic increases in scale and scope due to advances in DNA-sequencing technologies coupled with computational methods needed given the incredible information density of the microbiota [42-44]. Data are obtained predominantly from next-generation sequencing in three forms: A) ribosomal RNA (rRNA) gene sequence surveys that provide a view of microbiome membership, B) metagenomic data used to portray functional potential, and, C) metatranscriptomic data to describe active gene expression (for a review, readers are directed to [42]). Currently, 16 rRNA gene surveys are the most commonly used as they are substantially more economical and therefore scale to larger projects [44]. However, this technique is limited by short read lengths obtained, sequencing errors, and differences arising from the different regions chosen (e.g., hypervariable region V3 vs V4) [45]. 16 rRNA sequencing also has limited resolution and lower sensitivity compared to whole-community shotgun metagenomic analysis, such as characterization down to the genus level with minimal capability of species-level detection [46]. Therefore, shotgun metagenomics is displacing $16 \mathrm{~S}$ rRNA amplicon analysis because of its expanded taxonomic range and strain-level resolution [42].

Analyses used to interpret large data sets generated from these high-throughput sequencing techniques commonly include measures of biological diversity. Many of the studies included in this review measured alpha diversity which represents diversity within a sample. In calculating alpha diversity, various metrics (e.g., Shannon index, Chao1) consider the number of unique operational taxonomic units (OTUs), termed 'richness', and their relative abundance, termed 'evenness'. Also often used is beta-diversity, a measurement of how different the communities are between samples. Beta-diversity metrics are quantitative (e.g., weighted UniFrac), when considering samples phylogeny, and qualitative (e.g., uniweighted UniFrac) when only evaluating the presence/ absence of samples [47]. In addition, other 'omic' techniques, such as metabolomics, are being integrated with these data to provide deeper insights into host metabolism and health. Metabolomics uses high throughput techniques to characterize and quantify small molecules in several biofluids (urine, serum, plasma, feces, saliva), revealing a unique metabolic signature [48]. As a complement to sequencing-based approaches, the use of metabolomics (particularly from feces) is encouraged as it offers a 'functional' readout of the microbiome providing data on the metabolic interplay between the host, diet, exercise, and the gut microbiota $[49,50]$.

While the aforementioned techniques have allowed for a rapid increase in gut microbiota research, the variation in microbial analysis across different studies can make comparing/contrasting study findings difficult. Indeed, variation in profiling techniques (e.g., sequencing strategy, platform, variable regions, sequencing depth, etc.) may act as a confounding variable resulting in divergent findings due entirely to laboratory techniques rather than treatment [51]. Furthermore, many gut microbiota studies may be underpowered, and scientists may not be controlling for important confounding variables such as diet, gender, ethnicity, GI problems, antibiotics, etc. As the investigation of the athletic microbiota is a newer field of research, the intention of this review is to provide a broad overview of the current state of the literature. For future, more specific reviews, deeper discussions of methodological nuances are warranted.

\section{The athlete/exercise-associated gut microbiota}

Establishing consistent relationships across studies in physically active groups, such as athletes has been problematic. Beyond the obvious methodological differences such as sample preparation techniques, DNA sequencing, bioinformatics tools, and reference databases [5255], there is also large variation across exercise/athletic regimens. Moreover, confounding factors including training history, level of physical fitness, training environment, and dietary intake all have the potential to affect study outcomes substantially, and make detecting differences due to exercise/athletic regimens on the gut microbiota difficult to ascertain. Therefore, when comparing these individuals within or across various exercise/athletic disciplines and classifications, these factors should be accounted for and reported by investigators. While the current body of this comparative-type research is mixed and more limited (see Table 1), collectively it provides important insight and highlights key areas of future study.

\section{Athletes/physically active individuals vs other populations}

Several studies have investigated the difference in compositional gut microbiota between those physically active (including athletes) and a range of populations. While the above confounding factors are still relevant when 
Table 1 Athlete/exercise-associated gut microbiota in comparison to other populations or across athletic classification: Characteristics of included articles (by publication date)

\begin{tabular}{|c|c|c|c|c|c|}
\hline $\begin{array}{l}\text { Authors, } \\
\text { year, } \\
\text { country }\end{array}$ & Subjects & $\begin{array}{l}\text { Sex and } \\
\text { age }\end{array}$ & $\begin{array}{l}\text { Study design and } \\
\text { gut microbiome } \\
\text { analysis }\end{array}$ & Diet and/or exercise & Key outcome(s) \\
\hline $\begin{array}{l}\text { 1. Clarke } \\
\text { et al., 2014, } \\
\text { Ireland [19] }\end{array}$ & $\begin{array}{l}\text { Professional male rugby } \\
\text { athletes ( } n=40) \text { and healthy } \\
\text { size, age and sex matched } \\
\text { controls }(n=46)\end{array}$ & $\begin{array}{l}86 \\
\text { Males } \\
23-35 \\
\text { years }\end{array}$ & $\begin{array}{l}\text { Cross-sectional, } \\
\text { observational } \\
16 \mathrm{~S} \text { rRNA gene } \\
\text { amplification of the } \\
\text { V4 region }\end{array}$ & 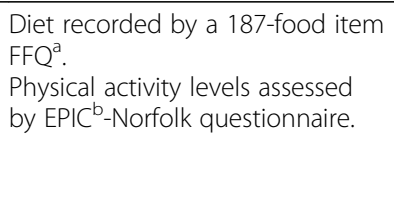 & $\begin{array}{l}\text { - Athletes had a higher } \mathrm{GM}^{\mathrm{c}} \\
\text { diversity compared to controls. } \\
\text { - Athletes in low BMl }{ }^{\mathrm{d}}\left(<25 \mathrm{~kg} / \mathrm{m}^{2}\right) \\
\text { group had higher proportions of } \\
\text { genus Akkermansia compared } \\
\text { with high BMI }\left(>28 \mathrm{~kg} / \mathrm{m}^{2}\right) \text { group }\end{array}$ \\
\hline
\end{tabular}

2. Bressa Healthy premenopausal $40 \quad$ Cross-sectional,

et al., 2017, women; active defined by Females observational

Spain [56] $\quad \mathrm{WHO}^{\mathrm{e}}(n=19)$ and sedentary 18-40 16S rRNA gene $(n=21)$
Acceleration, energy expenditure, intensity of physical activity and body position measured by Acti -Sleep V.3.4.2 accelerometer. Dietary pattern assessed by 97 food item FFQ.
3. Mörkl Anorexia nervosa patients et al., 2017, $\quad(n=18)$, athletes $(n=20)$,

Austria [57] normal weight $(n=26)$, overweight $(n=22)$, and obese women $(n=20)$.

4. Petersen Professional $(n=22)$ and et al., 2017, amateur $(n=11)$ level USA [18] competitive cyclists
106 Females observational

18-40 16S rRNA gene years amplification of the $\mathrm{V} 1$ and $\mathrm{V} 2$ regions

\section{Cross-sectional,}

22 Males/

11 Females 19-49 years RNA sequencing observational Metagenomic whole genome shotgun sequencing and 24-h recall dietary intake Activity level assessed by IPAQ score \& $\mathrm{MET}^{\mathrm{g}} / \mathrm{min}$

Exercise load (hours/week): 6-10; • No significant correlations 11-15; 16-20; and; $20+$.

Diet: equal protein, fat, carbohydrate; vegetarian; high complex carbohydrate; paleo; gluten-free. cyclists.
- Physical activity associated with increased the abundance of health-promoting bacteria (Bifidobacterium species, Roseburia hominis, A. muciniphila and

Faecalibacterium prausnitzii) in the microbiota.

- Inverse association between sedentary parameters and microbiota richness (number of species, and Shannon and Simpson indices).

- Lower microbial richness in obese and anorexic individuals compared to athletes.

$\begin{array}{lll}\text { 5. Barton } & \text { Professional male rugby } & 86 \\ \text { et al., 2018, } & \text { athletes }(n=40) \text { and healthy } & \text { Males } \\ \text { Ireland [13] } & \begin{array}{l}\text { size, age and gender } \\ \text { matched controls }(n=46)\end{array} & \begin{array}{l}23-35 \\ \text { years }\end{array}\end{array}$

6. Jang et al., 2019

South Korea [11]
Healthy sedentary men (as 45 controls; $n=15)$, bodybuilders Males $(n=15)$, and elite distance 19-28 years
Cross-sectional, observational Metagenomic whole genome shotgun sequencing and urine and fecal metabolomics

Cross-sectional, observational 165 rRNA gene amplification of the V3 and V4 regions FFQ

Physical activity levels assessed by EPIC-Norfolk questionnaire. Serum creatine kinase levels were used as a proxy for level of physical activity.

Physical activity level was assessed using the IPAQ. Dietary intake was analyzed with the computerized nutritional evaluation program.
Cross-sectional, observational Metagenomic whole genome shotgun sequencing and between taxonomic cluster and professional or amateur level

- High relative abundance of Prevotella in cyclists training $>11$ h/week.

- Increased abundance of Methanobrevibacter smithii transcripts in professional cyclists.

- The microbiota of athletes was more diverse than both the low and high BMI control groups at the functional level.

- Athletes had an enriched profile of SCFAs ${ }^{h}$ and higher levels of the metabolite TMAO'.

- Exercise type was associated with athlete diet patterns (bodybuilders: high-protein, highfat, low-carbohydrate, and lowdietary fiber diet; distance runners: low-carbohydrate and low dietary fiber diet). Athlete type was significantly associated with the relative abundance of gut microbiota at the genus and species level.

- Increased abundance of Faecalibacterium, Sutterella, Clostridium, Haemophilus, and Eisenbergiella in bodybuilders. - Athlete type did not differ in gut microbiota alpha and beta diversity.

- Microbial diversity did not differ between sport classification.

- Overall, samples dominated by species from one or a combination of five species: 
Table 1 Athlete/exercise-associated gut microbiota in comparison to other populations or across athletic classification: Characteristics of included articles (by publication date) (Continued)

\begin{tabular}{|c|c|c|c|c|c|}
\hline \multirow[t]{2}{*}{$\begin{array}{l}\text { Authors, } \\
\text { year, } \\
\text { country }\end{array}$} & Subjects & $\begin{array}{l}\text { Sex and } \\
\text { age }\end{array}$ & $\begin{array}{l}\text { Study design and } \\
\text { gut microbiome } \\
\text { analysis }\end{array}$ & Diet and/or exercise & Key outcome(s) \\
\hline & & years & $\begin{array}{l}\text { urine and fecal } \\
\text { metabolomics }\end{array}$ & & $\begin{array}{l}\text { Eubacterium rectale, } \\
\text { Polynucleobacter necessarius, } \\
\text { Faecalibacterium prausnitzii, } \\
\text { Bacteroides vulgatus and } \\
\text { Gordonibacter massiliensis. } \\
\text { - Athletes with high dynamic } \\
\text { component were associated with } \\
\text { greater abundance of } \\
\text { Bifidobacterium animalis, } \\
\text { Lactobacillus acidophilus, Prevotella } \\
\text { intermedia and F. prausnitzii. } \\
\text { - Athletes with both a high } \\
\text { dynamic and statick component } \\
\text { were associated with greater } \\
\text { abundance of Bacteroides caccae. }\end{array}$ \\
\hline
\end{tabular}

${ }^{\mathrm{a}} F F Q$ Food frequency questionnaire

${ }^{b} E P I C$ European Prospective Investigation of Cancer

${ }^{\circ} G M$ Gut microbiota

${ }^{\mathrm{d}} B M I$ Body mass index

${ }^{\mathrm{e}} W H O$ World Health Organization

fIPAQ International Physical Activity Questionnaire

${ }^{9} M E T$ Metabolic equivalent

${ }^{\mathrm{h}}$ SCFA Short-chain fatty acid

iTMAO Trimethylamine $\mathrm{N}$-oxide

'Dynamic Classified by estimated $\mathrm{VO}_{2}$ max

${ }^{\mathrm{k}}$ Static Classified by maximal voluntary contraction

interpreting these studies, such research provides an important comparator to the gut microbiota of these individuals. In an observational study, the gut microbiotas of sedentary and physically active premenopausal women were compared [56]. Physical exercise was not related to differences in the microbiota diversity or richness (the total number of OTUs or species recorded); however, sedentary parameters (i.e., sedentary time and breaks) correlated negatively with microbiota richness. Further, quantitative polymerase chain reaction analysis revealed higher abundance of health-promoting bacterial species in active women, including Faecalibacterium prausnitzii, Roseburia hominis and Akkermansia muciniphila. In another cross-sectional study in females, Mörkl et al. [57] compared the gut microbiota of anorexia nervosa inpatients to recreational athletes from a range of sports and overweight, obese, and normal weight controls. Microbiota diversity was markedly lower in anorexia nervosa patients and obese participants compared to other groups, while athletes showed the highest alpha diversity (species richness). Interestingly, total fat mass, serum lipids, C-reactive protein, depression scales, and smoking status were negatively associated $\left(R^{2}=-0.012\right.$ to $0.256, P<0.05)$ with microbiota diversity. It is important to note that these associations are likely driven by lifestyle. While caution should be used in interpreting this data given the cross-sectional nature and inability to account for other potential influences, investigation of gut microbiota composition, diversity, and function should be useful in characterizing key elements of a healthy lifestyle.

Clarke et al. [19] reported the gut microbiota of professional male rugby players was more diverse than healthy, non-athlete subjects matched for body mass index (BMI), age, and gender. Given the physical size of modern rugby players, two control groups were assessed; one matched for athlete size with a comparable (elevated) BMI $\left(>28 \mathrm{~kg} / \mathrm{m}^{2}\right)$ and a second reflecting the background age-matched and sex-matched population (lower BMI of $<25 \mathrm{~kg} / \mathrm{m}^{2}$ ). Importantly, the alpha diversity of the elite athlete's microbiota was higher than that of both control groups. Further, the athletes and those in the low BMI control group had higher proportions of the genus Akkermansia than the high BMI control group. Moreover, protein consumption was correlated positively $(R=0.24-0.43)$ with microbial diversity across all groups, indicating that greater protein intake was linked to higher levels of microbial diversity. There is a possibility that the increased diversity of the athlete's gut microbiota was due, in part, to their higher protein intake. Barton et al. [13] re-examined the microbiota in these participants using whole metagenome shotgun sequencing to provide deeper insight into taxonomic composition and metabolic potential. Differences in fecal microbiota between athletes and sedentary controls showed even greater separation at the metagenomic and metabolomic level than at the gut microbiota compositional level. Relative to controls athletes appear to have 
increases in metabolic pathways (e.g., amino acid and antibiotic biosynthesis and carbohydrate metabolism) and fecal metabolites (e.g., microbial produced shortchain fatty acids (SCFAs) including acetate, propionate, and butyrate) associated with enhanced fitness and overall health when compared to control groups [13].

\section{Athletes across different classifications and disciplines}

To explore possible differences between levels of athletes, Petersen et al. [18] investigated the gut microbiotas of 22 professional and 11 amateur competitive cyclists. Using metagenomic whole genome shotgun sequencing, no significant correlations were evident between the taxonomic clusters in professional or amateur cycling status. However, the amount of exercise (time reported exercising during the average week) was correlated positively with a greater abundance of the genus Prevotella ( $\geq 2.5 \%)$. Increased abundance of Prevotella, common in non-Western populations and associated with plant/fiber rich diets, was further positively correlated with several amino acid and carbohydrate metabolism pathways, including branched-chain amino acid (BCAA) metabolism. Using metatranscriptomic sequencing, there was increased abundance of Methanobrevibacter smithii transcripts in a number of the professional cyclists in comparison to amateur cyclists. Moreover, this archaeon had upregulation of genes involved in the production of methane and when methane metabolism was upregulated, there was similar upregulation of energy and carbohydrate metabolism pathways. Similar to Clarke et al. [19], there was low abundance of Bacteroides in the athletes. In addition, Akkermansia was present in 30 out of 33 cyclists, with seven cyclists having relative abundances $>2 \%$ of this microbe in their metagenomic community. These outcomes may have been a reflection of higher fitness/metabolism of these athletes as increased proportions of Akkermansia are generally associated with a healthier metabolic profile [59].

To examine the gut microbiota and metabolome across sport classification, O'Donovan and colleagues [58] collected fecal and urine samples from 37 elite Irish athletes across 16 different sports (many of whom were participating in the 2016 Summer Olympics). To gain an understanding of the impact of dynamic (classified by estimated $\mathrm{VO}_{2} \mathrm{max}$ ) versus static (classified by maximal voluntary contraction) components of exercise, each sport was classified into a broader sports classification group. Fecal samples were prepared for shotgun metagenomic sequencing and fecal and urine samples underwent metabolomic profiling. Athletes participating in sports with a high dynamic component were the most distinct compositionally (greater differences in proportions of species; see Table 1), while athletes participating in sports with both a high dynamic and static component were the most functionally distinct (greater differences in functional potential). Fecal and urine derived metabolites also varied between classification including increased lactate (urine) in sports with a static component and creatinine (feces) in sports with a high dynamic and low static component. While increased lactate in the more static-based sports was not surprising, increased creatinine in more dynamic-based sports was. It may have been that the dynamic exercises in this athletic cohort involved substantial muscle turnover, potentially resulting in the increase in the production of creatinine. It is unclear what the causative factors of this finding and other reported differences in the gut microbiota and metabolome were due to the sampling variation, sample size and cross-sectional nature of this study. However, these differences were observed despite no significant variation in dietary intakes across athletes from different classifications; suggesting that variations in training loads and competition requirements contributed to these microbiome and metabolome-related patterns.

To investigate the long-term effects of a specific exercise type and athletes' diets on gut microbiota, Jang et al. [11] compared fecal microbiota characteristics, dietary intake, and body composition in 15 healthy sedentary men (as controls), 15 bodybuilders, and 15 distance runners. Exercise type was associated with athlete diet patterns (i.e., bodybuilders: high-protein, high-fat, and lowcarbohydrate/dietary fiber diet; distance runners: lowcarbohydrate and low-dietary fiber diet). While athlete type did not differ regarding gut microbiota alpha and beta diversity, it was significantly associated with the relative abundance of several bacteria. For instance, at the genus level, Faecalibacterium, Sutterella, Clostridium, Haemophilus, and Eisenbergiella were the highest, while Bifidobacterium and Parasutterella were the lowest in bodybuilders. At the species level, intestinal beneficial bacteria widely used as probiotics (Bifidobacterium adolescentis, Bifidobacterium longum, Lactobacillus sakei) and those producing short chain fatty acids (Blautia wexlerae, Eubacterium hallii) were the lowest in bodybuilders and the highest in controls. In distance runners, protein intake was negatively correlated with diversity (Shannon index $R=-0.63 ; P=0.01)$ and in bodybuilders, fat intake was negatively correlated with Bifidobacteria $(R=-0.52 ; P=$ 0.05 ). These differences may relate to the nutrition status of athletes in the study (i.e. insufficient carbohydrate and dietary fiber; higher fat).

\section{Summary of the athlete/exercise-associated gut microbiota}

From the limited evidence, it appears that athletes harbor an increased abundance of functional pathways within the microbiome that are exploited by the host for potential health benefits, as well as carbohydrate degradation and secondary metabolite metabolism compared to control groups [60]. While difficult to isolate, the 
influence of dietary intake on many of these differences is likely and needs to be considered in the context of this research. Furthermore, athletes have an enriched profile of SCFAs, previously associated with numerous health benefits and a lean phenotype [61-63]. This profile along with an increased number of detected SCFA pathways in athletes is conducive to an enhanced rate of SCFA production [64]. While evidence is currently limited, results from Clarke et al. [19] and Petersen et al. [18] suggest $A$. muciniphilia may be more present in athletes than non-athletes. A. muciniphilia is a mucindegrading bacterium that resides in the nutrient-rich mucus layer of the gut that appears to be associated with positive metabolic function [59]. A. muciniphilia levels are decreased in obese and type 2 diabetic mice, and treatment with these bacteria reversed high-fat dietinduced metabolic disorders, including fat mass gain, metabolic endotoxemia, adipose tissue inflammation, and insulin resistance [65]. A. muciniphilia can control mucus production by the host and restore mucus layer thickness in mice with high-fat diet-induced obesity, thereby reducing gut permeability. This outcome led to the hypothesis that $A$. muciniphilia engages in cross-talk with the intestinal epithelium to control inflammation and gut barrier function [65]. A. muciniphilia has also been found to be enriched in mice fed a ketogenic diet, exhibiting gut-brain functions including conferring seizure protection in two preclinical models for refractory epilepsy [66]. While the role of A. muciniphila is less certain in humans, it is depleted in individuals with several metabolic and inflammatory disorders. For example, of subjects undergoing dietary calorie restriction treatment for obesity, those with higher levels of these bacteria exhibited the best metabolic status and clinical outcomes [59]. Future research in athletes should continue to investigate the role $A$. muciniphilia plays in the gut microbiota and its functional impact on metabolism.

In relation to obesity, some athletes who may be defined as physically active may not necessarily be healthier based on BMI [67]. For example, Rugby or American football players commonly have large amounts of lean mass, and many will have relatively healthy percent body fat levels, typically $12-20 \%$, so BMI is considered to be a poor measure of obesity status in these athletic cohorts. While Clarke et al. [19] and Barton et al. [13] compared the gut microbiome of athletes to matched controls considered overweight by BMI, future work should also investigate this comparison at the obese classification. Findings from such research could provide important data in connection with the pathogenesis of obesity and the gut microbiota. One leading theory on the pathogenesis of obesity emphasizes a close link between the metabolic and immune systems via the gut microbiota [68]. This body of work suggests that increased intestinal permeability from high-fat / high sugar diets allows bacterial lipopolysaccharide (LPS), an outer membrane component of gram-negative bacteria linked with induction of inflammation, from the gut microbiota to translocate into the systemic circulation, resulting in systemic endotoxemia. Activation of pro-inflammatory cytokines is observed, leading to the chronic low-grade inflammation often implicated in obesity [69]. In contrast, athletes have been noted to have lower levels of circulating LPS compared to sedentary individuals [70]. These findings support of the notion that other factors beyond BMI levels should be considered when assessing any relationship between metabolic health, obesity and the microbiome status of competitive athletes.

Barton et al. [13] speculated that the athlete gut microbiome may possess a functional capacity primed for tissue repair and a greater ability to harness energy from the diet with increased capacity for carbohydrate metabolism, cell structure, and nucleotide biosynthesis. This assertion reflects the significant energy demands and tissue adaptation that occurs during intense exercise and elite sport. It appears that being physically active is another important factor in the relationship between the microbiota and host metabolism. Intervention-based studies to delineate this relationship will be important and provide further insights into optimal therapies to influence the gut microbiota, and its relationship with health and disease as well as athletic performance.

\footnotetext{
Key Points 1 - Athlete/exercise-associated microbiota

- Although limited in evidence, active individual's microbiota display a higher abundance of health-promoting bacterial species such as $A$. muciniphila and increased diversity.

- Body composition and physical activity are positively correlated with several bacterial populations.

- Investigating metagenomic functions rather than taxonomy alone provides a more meaningful understanding of gut microbiota and the impact of microbial metabolic functions on human physiology.

- Athletes have more fecal metabolites (e.g., microbial SCFAs including acetate, propionate, and butyrate) associated with enhanced muscle turnover (fitness) and overall health than less active individuals. These differences are likely driven by the effects of exercise training and/or dietary intake.

- The athlete/exercise-associated gut microbiome may possess a functional capacity primed for tissue repair and a greater ability to harness energy from the diet with increased capacity for carbohydrate metabolism, cell structure, and nucleotide biosynthesis.
}

\section{The effect of exercise on the gut microbiota Animal research}

Few studies have focused on the impact that voluntary exercise has on gut microbiota and, to date, all but seven of these experimental studies utilized murine models $[17,71]$. These preliminary studies indicate that exercise influences the composition of the gut microbiota 
community. Matsumoto et al. [72] reported that regular running exercise in rats was related to an increase in butyrate-producing bacteria in the microbiota composition along with an increase of butyrate concentration. Other animal studies demonstrated that daily wheel running exercise may improve some aspects of unhealthy states, such as diet-induced obesity, diabetes, and toxicity, by impacting the gut microbial composition in mice [73-75]. These effects included altering the ratio between the dominant phyla Firmicutes and Bacteroidetes, which has been found to be correlated with obesity and other diseases [76-78]. Animal and human data have reported that the Firmicutes/Bacteroidetes ratio is higher (i.e., increased Firmicutes and/or decreased Bacteroidetes) in obese people compared to lean people [79-82]. However, this is not always the same between studies [83, 84] and may be an oversimplification of phylum-level patterns in relation to host health. Further, mechanisms by which specific members of the microbiota, such as Firmicutes and Bacteroidetes, can affect human phenotypes remain to be fully elucidated [85]. Therefore, changes in phyla ratios should be interpreted with caution.

Amongst the exercise studies in animals there was little agreement regarding what taxa are influenced by chronic exercise. Other than a positive correlation between exercise and Lactobacillus [73, 86, 87], there are no other taxa that consistently increase in relative abundance in regularly exercised mice or rats. In particular, Choi et al. [73] reported that, in comparison to a sedentary control, mice with running wheel exercise had higher phylum Firmicutes but fewer phyla Tenericutes and Bacteroidetes, which attenuated changes in gut microbiota induced by oral exposure to the environmental toxin, polychlorinated biphenyls. Lambert et al. [75] described that exercised mice presented a greater abundance of Firmicutes species and lower Bacteroides/Prevotella genera compared with sedentary mice. In contrast, Evans et al. [74] concluded that exercise increased Bacteroidetes, while it decreased Firmicutes in mice, implying that exercise plays an important role in prevention of diet-induced obesity producing a microbial composition similar to lean mice. The changes in the Firmicutes/Bacteroidetes ratio exerted by exercise were inversely proportional to the distance traveled by animals [74]. Campbell et al. [88] asserted that exercised mice have bacteria related to Faecalibacterium prausnitzii which may protect the digestive tract by producing butyrate and lowering the oxygen tension in the lumen by a flavin/thiol electron shuttle. Briefly, the health-related effects of butyrate are associated with anti-inflammatory properties, direct feeding of colonocytes, and an impact on satiety [64]. Notably, butyrate, along with propionate and acetate, provides
$10 \%$ of the daily caloric requirements in humans who consume high $(\sim 60 \mathrm{~g} /$ day $)$ amounts of dietary fiber [64]. The bacterial abundance of Clostridiaceae and Bacteroidaceae families and Ruminoccocus genus were negatively associated with blood lactate levels in exercised animals, whereas a positive association was reported for Oscillospira genus [86].

Moreover, it seems that the changes exerted by physical exercise depend on the physiological state of the individual. For example, regular forced exercise differentially affected microbiota richness whether they were obese-hypertensive or normal rats [86]. Alterations to the microbiota exerted by exercise in rats following a high-fat diet were different to rats on a normal diet [89], as well as the alterations produced in diabetic mice were different to their control counterparts [75]. Collectively, these findings indicate that modulation of the microbiota by chronic exercise depends not only on the physiological state of the individual, but also on the diet. Moreover, another significant difference between forced vs. voluntary exercise in animals is exercise volume. This is recapitulated in human cyclist data [18] and requires further investigation in animal models. Finally, it has been observed that exercise induces more effective changes in the microbiota in juvenile rats than in adult rats [90]. A common finding in these murine studies examining the effects of exercise training on the gut microbiome, is an increase in alpha diversity [17]. Several other studies using murine-based models also demonstrated increased alpha diversity in animals that exercised vs. those that were sedentary $[73,74,86,87]$.

\section{Cross-sectional research in humans}

In healthy individuals, Estaki et al. [14] reported higher cardiorespiratory fitness (as measured by peak or maximum oxygen uptake, $\mathrm{VO}_{2}$ peak or $\mathrm{VO}_{2} \max$ ) correlated with increases in both microbial diversity and fecal butyrate (see Table 2). Also identified was a core set of gene related functions rather than a core set of bacterial taxa in individuals with high levels of fitness [14]. Further, $\sim 20 \%$ of the variation in gut bacterial alpha diversity could be explained by $\mathrm{VO}_{2}$ peak alone; in fact, $\mathrm{VO}_{2}$ peak stood as the only variable that contributed significantly to increased alpha diversity. The primary findings indicate that cardiorespiratory fitness is a good predictor of gut microbial diversity in healthy humans, outperforming several other variables including sex, age, BMI, and multiple dietary components. Additionally, enhanced bacterial diversity was correlated positively with certain microbial metabolic functions including chemotaxis, motility, and fatty acid biosynthesis. As $\mathrm{VO}_{2}$ peak was not significantly associated with variation in community composition, this result suggests function may be a better predictor than species richness, as noted 
Table 2 Effect of exercise and/or athletic diet on the gut microbiota: Characteristics of included articles (by publication date)

\begin{tabular}{lllll}
\hline $\begin{array}{l}\text { Authors, } \\
\text { year, }\end{array}$ & Subjects characteristics & $\begin{array}{l}\text { Study design and gut } \\
\text { microbiome analysis }\end{array}$ & Diet and/or exercise & Duration
\end{tabular}

year, country

\section{Clarke}

et al.,

2014,

Ireland

[19]

$\begin{array}{ll}\text { 2. Estaki } & \text { Healthy young males and } \\ \text { et al., } & \text { females, } n=39, \text { stratified by } \\ \text { 2016, } & \text { cardiorespiratory fitness, Low: } \\ \text { Canada } & 25.5 \pm 3.3 \text { years; Average: } \\ \text { [14] } & 24.3 \pm 3.7 \text { years; High: } 26.2 \pm \\ & \text { 5.5 years }\end{array}$

Cross-sectional

165 rRNA gene

amplification of the $\mathrm{V} 3$ and

$\checkmark 4$ regions $\begin{array}{ll}\text { 3. Yang } & \text { Premenopausal females with } \\ \text { et al., } & \text { low, moderate and high- } \\ \text { 2017, } & \text { cardiorespiratory fitness } \\ \text { Finland } & \left(\mathrm{VO}_{2} \text { max }\right), n=71, \mathrm{Low} \\ \text { [94] } & \mathrm{VO}_{2} \text { max: } 40.4 \pm 3.5 \text { years; } \\ & \text { Moderate } \mathrm{VO}_{2} \text { max: } 39.7 \pm 4.2 \\ & \text { years; } \\ & \text { High } \mathrm{VO}_{2} \text { max: } 30.6 \pm 5 \text { years }\end{array}$

4. Allen Sedentary lean males and

et al., females, $n=18,25.1 \pm 6.52$

2018, USA years; Obese males and

[98] females, $n=14,31.14 \pm 8.57$ years
Longitudinal design

$16 S$ rRNA gene V4 region amplification of the

$\begin{array}{ll}\text { Observational } & \begin{array}{l}\text { Cross- } \\ \text { sectional }\end{array}\end{array}$

- Athletes had a higher

diversity of gut microorganisms, representing 22 distinct phyla.

- GMa diversity indices were positively correlated with protein intake and serum creatine kinase in athletes.

Observational

Crosssectional

- $\mathrm{VO}_{2}$ peak ${ }^{\mathrm{b}}$, independent of diet, positively correlated with increased GM diversity.

- $\mathrm{VO}_{2}$ peak explained significant variation in GM predicted metagenomic functions, aligning positively with genes related to bacterial chemotaxis, motility, and fatty acid biosynthesis.

- Increased production of fecal butyrate abundances of butyrate-producing taxa (Clostridiales, Roseburia, Lachnospiraceae, and Erysipelotrichaceae) amongst physically fit participants.

Cross-sectional $16 S$ rRNA hybridization, DNA-staining, and flow cytometry

Observational

Crosssectional

Decreased Bacteroides, increased Eubacterium rectale-Clostridium coccoides in low $\mathrm{VO}_{2}$ max participants vs high $\mathrm{VO}_{2}$ max participants.

- $\mathrm{VO}_{2}$ max inversely associated with Eubacterium rectale-C. coccoides but not with other bacteria.

30-60 min moderate-to6 weeks vigorous intensity $(60-75 \%$ of $\mathrm{HRR}^{\mathrm{C}}$ ) aerobic exercise, $3 x$ per week

- Exercise induced shifts in SCFA ${ }^{\text {d-producing taxa }}$ (Faecalibacterium and Lachnospira species) and genetic machinery $\left(\mathrm{BCOAT}^{\mathrm{e}}\right)$ were more substantial in lean versus obese participants.

- A return to sedentary activity for 6 weeks led to a $\mathrm{BMI}^{\mathrm{f}}$-dependent reversion in gut microbiome composition.

5. Barton Professional male rugby et al., $\quad$ players, $n=40,29 \pm 4$ years; 2018, Healthy matched controls, Ireland $n=46,29 \pm 6$ years

2018 18-40 years

Ireland

Cross-sectional
Metagenomic whole genome shotgun sequencing and urine and fecal metabolomics
Observational

Crosssectional

Randomized controlled trial,

parallel group design Metagenomic whole genome shotgun
Groups:

- Protein-only; $30 \mathrm{~g}$ protein (24 g whey)

- Exercise-only; Combined aerobic and resistance

- Relative increase in pathways (amino acid and antibiotic biosynthesis and carbohydrate metabolism) in athletes vs control.

- Increase in fecal metabolites (acetate, propionate and butyrate) in athletes vs control.

8 weeks $\quad$ Increase in alpha diversity in Exercise + Protein group vs Protein group.

- Decrease in beta diversity of the gut virome in 
Table 2 Effect of exercise and/or athletic diet on the gut microbiota: Characteristics of included articles (by publication date) (Continued)

\begin{tabular}{|c|c|c|c|c|c|}
\hline $\begin{array}{l}\text { Authors, } \\
\text { year, } \\
\text { country }\end{array}$ & Subjects characteristics & $\begin{array}{l}\text { Study design and gut } \\
\text { microbiome analysis }\end{array}$ & Diet and/or exercise & Duration & Key outcome(s) \\
\hline & & $\begin{array}{l}\text { sequencing and urine and } \\
\text { fecal metabolomics }\end{array}$ & $\begin{array}{l}\text { training (aerobic training of } \\
\text { moderate intensity and re- } \\
\text { sistance training of } 3 \text { sets of } \\
8 \text { repetitions on } 7 \text { different } \\
\text { resistance machines) } 3 \times \text { per } \\
\text { week } \\
\text { - Exercise + protein }\end{array}$ & & $\begin{array}{l}\text { participants consuming } \\
\text { protein. }\end{array}$ \\
\hline $\begin{array}{l}7 . \\
\text { Moreno- } \\
\text { Pérez } \\
\text { et al., } \\
2018,\end{array}$ & $\begin{array}{l}\text { Endurance-trained } \\
\text { males, } n=18 \\
35.38 \pm 9.0 \text { years (control } \\
\text { group), } 34.90 \pm 9.49 \text { years } \\
\text { (protein group) }\end{array}$ & $\begin{array}{l}\text { Randomized controlled } \\
\text { trial, } \\
\text { parallel group design } \\
16 \mathrm{~S} \text { rRNA gene } \\
\text { amplification of the V3 and }\end{array}$ & $\begin{array}{l}\text { Groups: } \\
\text { - Control: maltodextrin } \\
\text { - Protein: blend of whey } \\
\text { isolate }(10 \mathrm{~g}) \text { and beef } \\
\text { hydrolysate }(10 \mathrm{~g})\end{array}$ & 10 weeks & $\begin{array}{l}\text { - Increase in Bacteroidetes in } \\
\text { protein group. } \\
\text { - Decrease in Roseburia, } \\
\text { Blautia, and Bifidobacterium } \\
\text { longum in protein group. }\end{array}$ \\
\hline
\end{tabular}

[196]

8. Healthy elderly Japanese

Taniguchi males, $n=33,62-76$ years

et al.,

2018,

Japan

[101]

\section{$\checkmark 4$ regions}

Randomized crossover tria $16 \mathrm{~S}$ rRNA gene amplification of the $\mathrm{V} 3$ and $\checkmark 4$ regions
Minimum training frequency

of 5 endurance training sessions per week; $\geq 240$ min per week

5-week control period OR 5- 5 weeks week supervised, progressive aerobic exercise program. Cycle ergometer $3 x$ per week. $60 \%$ of pre exercise $\mathrm{VO}_{2}$ peak during week 1, $70 \%$ during weeks 2 and 3, and 75\% during weeks 4 and 5. Duration was 30 min for weeks 1 and 2, and 45 min for weeks 3-5. $\begin{array}{ll}\text { 9. Durk } & \text { Healthy young males and } \\ \text { et al., } & \text { females, } n=37,25.7 \pm 2.2 \\ \text { 2019, USA } & \text { years } \\ \text { [93] } & \end{array}$
Cross-sectional

Quantitative Polymerase

Chain Reaction (qPCR) that specifically measured the quantity of a target gene (16s RNA) found in

Firmicutes and Bacteroidetes

A prospective, repeatedmeasures, within-subject report Metagenomic whole genome shotgun sequencing
Observational

\section{Observational} athletes, $n=4$,

et al., $\quad 26.5 \pm 1.3$ years

2019,

Ireland

[99]

Randomized controlled trial, parallel group design $16 S$ rRNA gene amplification of the $V_{4}$ region
11. Kern Overweight/obese males and et al., 2019, Denmark [108] females; $n=88 ; 20-45$ years
Exercise groups:

- Habitual living (CON),

- Active commuting by bike (BIKE)

- Leisure-time exercise of moderate intensity (MOD)
- Short-term endurance exercise did not appreciably influence diversity and composition of gut microbiota. Minor changes in the gut microbiota were associated with cardiometabolic risk factors.

- Decreased relative abundance of $C$. difficile significantly decreased, whereas Oscillospira significantly increased during exercise as compared to the control period.

- Firmicutes/Bacteroidetes ratio positively correlated to $\mathrm{VO}_{2}$ max.

- $\mathrm{VO}_{2}$ max explained $\sim 22 \%$ of the variance of an individual's relative gut bacteria as determined by Firmicutes/Bacteroidetes ratio.

33-day event; 3month follow-up

- Increased alpha diversity throughout event.

- Increased abundance of butyrate producing species (Roseburia hominis and members of the genus Subdoligranulum) and species associated with improved metabolic health (Dorea longicatena).

- Many of the adaptions in GM community structure and metaproteomics persisted at 3 months follow up.

6 months $\quad$ Increase alpha diversity index in VIG at 3 months compared with CON.

- Beta diversity changed in all exercise groups compared with CON; VIG decreased 
Table 2 Effect of exercise and/or athletic diet on the gut microbiota: Characteristics of included articles (by publication date) (Continued)

\begin{tabular}{|c|c|c|c|c|c|}
\hline $\begin{array}{l}\text { Authors, } \\
\text { year, } \\
\text { country }\end{array}$ & Subjects characteristics & $\begin{array}{l}\text { Study design and gut } \\
\text { microbiome analysis }\end{array}$ & Diet and/or exercise & Duration & Key outcome(s) \\
\hline
\end{tabular}

\begin{tabular}{|c|c|}
\hline $\begin{array}{l}\text { 12. Morita } \\
\text { et al., } \\
2019, \\
\text { Japan } \\
\text { [103] }\end{array}$ & $\begin{array}{l}\text { Healthy sedentary elderly } \\
\text { females; } n=32 ; \geq 65 \text { years }\end{array}$ \\
\hline $\begin{array}{l}13 . \\
\text { Motiani } \\
\text { et al., } \\
2019, \\
\text { Finland } \\
\text { [109] }\end{array}$ & $\begin{array}{l}\text { Obese sedentary, } \\
\text { prediabetic/type } 2 \text { diabetic } \\
\text { males and females; } n=26 \\
(n=9, n=17 \text { respectfully); } \\
49 \pm 4 \text { years }\end{array}$ \\
\hline
\end{tabular}

- Vigorous intensity exercise (VIG)

Non-randomized comparative trial $16 S$ rRNA terminal restriction fragment length polymorphism analyses

Parallel group design 165 rRNA gene amplification of the V3 and $\checkmark 4$ regions

\begin{abstract}
14.
Murtaza

et al.,
\end{abstract}

2019,

Australia

[230]
Elite male endurance race walkers; $n=21 ; 20-35$ years

Non-randomized

comparative trial

16S rRNA gene

amplification of the V6-V8 regions
Exercise groups:

- Trunk muscle training group

$1 \mathrm{~h}$ per week.

- Aerobic exercise training group, brisk walking at $\geq 3$ METS $^{g}, 1$ h daily.

Exercise groups:

- Sprint interval training group; 30 s exercise bouts (4-6) of all out cycling efforts with 4 min of recovery, $3 x$ a week.

- Moderate intensity continuous training group; 40-60 min cycling at $60 \%$ of $\mathrm{VO}_{2}$ peak intensity, $3 \mathrm{x}$ a week.

Diet groups:

- High-Carbohydrate

- Periodized Carbohydrate

- ketogenic LCHF

Consumed during an intensified training program.

3 weeks

12 weeks

heterogeneity.

- Increased inferred functional potential of microbiota in the exercise groups, primarily at 3 months and in MOD.

- Increased Bacteroides relative abundance in aerobic exercise group.

- Increased Bacteroides following exercise intervention associated with increased 6-min walk test.

- Increased Bacteroidetes in both groups.

- Decreased Firmicutes: Bacteroidetes ratio in both groups.

- Decreased Clostridium genus and Blautia.

- Colonic glucose uptake positively associated with Bacteroidetes and inversely with Firmicutes phylum, Firmicutes: Bacteroidetes ratio and Blautia genus.

- Microbiota profiles at baseline could be separated by Prevotella or Bacteroides dominated enterotype.

- LCHF diet resulted in increased relative abundance of Bacteroides and Dorea and decreased Faecalibacterium.

- Negative correlations between Bacteroides and fat oxidation, and between Dorea and economy test following LCHF intervention.

15. Experiment 1:

Scheiman Athletes from the 2015

et al., Boston Marathon $(n=15)$,

2019, USA sedentary controls $(n=10)$

[16] Experiment 2:

- Ultramarathoners and

Olympic trial rowers $(n=87)$
Observational

\section{S rRNA gene}

amplification of the V4

region for experiment 1

Metagenomic whole genome shotgun

sequencing for experiment 2
Experiment 1:

- Marathon event

Experiment 2:

- Exercise bout
16. Liu

et al.,

2019,

China
Overweight/obese

prediabetic males; $n=39$;

20-60 years
Randomized controlled

trial,

parallel group design

Metagenomic whole
Groups:

- Control; No exercise.

- High-intensity exercise; 70 min combined aerobic and
Experiment

1:

- Fecal

samples

collected 7

days before

and after

Marathon

event

Experiment

2:

- Pre/post

exercise

12 weeks

Experiment 1:

- Increased Veillonella relative abundance in marathon runners post marathon.

- Veillonella was more prevalent among runner's vs non-runners, although this was not statistically significant.

Experiment 2:

- Increased Veillonella abundance post exercise.

- Veillonella methylmalonylCoA pathway was overrepresented in athlete metagenomic samples post exercise.

- Microbiota profiles were differentially altered in exercise responders $(n=14)$ vs non-responders $(n=6)$. 
Table 2 Effect of exercise and/or athletic diet on the gut microbiota: Characteristics of included articles (by publication date) (Continued)

\begin{tabular}{|c|c|c|c|c|c|}
\hline $\begin{array}{l}\text { Authors, } \\
\text { year, } \\
\text { country }\end{array}$ & Subjects characteristics & $\begin{array}{l}\text { Study design and gut } \\
\text { microbiome analysis }\end{array}$ & Diet and/or exercise & Duration & Key outcome(s) \\
\hline$[106]$ & & $\begin{array}{l}\text { genome shotgun } \\
\text { sequencing and fecal } \\
\text { metabolomics }\end{array}$ & $\begin{array}{l}\text { resistance interval training, } \\
3 x \text { a week. }\end{array}$ & & $\begin{array}{l}\text { - The microbiome of } \\
\text { responders had increased } \\
\text { functional capacity for SCFA } \\
\text { biosynthesis and BCAA } \\
\text { catabolism. } \\
\text { - Exercise-induced gut micro- } \\
\text { biota changes were posi- } \\
\text { tively correlated with } \\
\text { improvements in glucose } \\
\text { homeostasis and insulin } \\
\text { sensitivity. } \\
\text { - Baseline microbiome } \\
\text { features accurately } \\
\text { predicted personalized } \\
\text { exercise responses. } \\
\text { - Fecal microbiota } \\
\text { transplantation from } \\
\text { responders conferred the } \\
\text { metabolic benefits of } \\
\text { exercise in mice. }\end{array}$ \\
\hline
\end{tabular}

${ }^{\mathrm{a}} \mathrm{GM}$ Gut microbiota

${ }^{\mathrm{b}} \mathrm{VO}_{2}$ Volume of oxygen utilization

${ }^{\mathrm{C}} H R R$ Heart rate reserve

${ }^{\mathrm{d}}$ SCFA Short-chain fatty acid

${ }^{\mathrm{e}} B C O A T$ Butyryl-CoA:acetate CoA-transferase, a butyrate-regulating gene

${ }^{\mathrm{f}} \mathrm{BM}$ I Body mass index

${ }^{9}$ METS Metabolic equivalents

${ }^{\mathrm{h}}$ LCHF Low-Carbohydrate High-Fat

'BCAA Branched-chain amino acid

previously. This study also confirmed results by Matsumoto and colleagues [72] who initially reported that exercising rats exhibited a positive correlation between high-cardiorespiratory fitness and an increase in the SCFA, butyrate. Increases in fecal butyrate were observed when relative abundances of Clostridiales, Roseburia, Lachnospiraceae, and Erysipelotrichaceae were increased [14]. These SCFAs are derived from fermentation of undigested plant fiber by the microbiota in the large intestine.

Functional categories most strongly correlated with $\mathrm{VO}_{2}$ peak were related to bacterial motility (bacterial motility proteins, flagella assembly, and bacterial chemotaxis), sporulation, and to a lesser extent the twocomponent system known to enable bacterial communities to sense and respond to environmental factors [14]. One possible mechanism behind these associations may be derived from the observation that butyrate, which was more abundant among participants with higher cardiorespiratory fitness, can modulate neutrophil chemotaxis [91]. $\mathrm{VO}_{2}$ peak was inversely correlated with LPS biosynthesis and LPS biosynthesis proteins which were elevated among less fit participants. LPS is a major component of the cell wall of gram-negative bacteria and considered an endotoxin when present in the blood. By binding to extracellular toll-like receptor 4 located on many cell types, LPS elicits strong inflammatory responses that may be detrimental to the host. Continuous low-level translocation of LPS into circulation can induce chronic low-level inflammatory states associated with development of obesity and other metabolic syndromes [92]. These inflammatory states are thought to be derived to some extent from inflammatory responses to blood LPS which is elevated in sedentary humans [70]. Exercise training attenuates inflammation in part by reducing elevated blood LPS [70]. The inverse relationship between $\mathrm{VO}_{2}$ peak and LPS biosynthesis pathways implies a beneficial consequence of increased physical activity which may result in decreased LPS biosynthesis.

Durk et al. [93] also explored the relationship between cardiorespiratory fitness and relative gut microbiota composition in healthy young adults showing that Firmicutes/Bacteroidetes ratio was significantly positively correlated to $\mathrm{VO}_{2}$ max. While no other relationships between the gut microbiota and fitness, nutritional intake, or anthropometric variables were found, $\mathrm{VO}_{2} \max$ accounted for $\sim 22 \%$ of the variance of an individual's relative gut bacteria (as determined by the Firmicutes/ Bacteroidetes ratio). In a cross-sectional study in premenopausal women, cardiorespiratory fitness was associated with gut microbiota composition, independent of 
age and carbohydrate or fat intake [94]. Participants with low $\mathrm{VO}_{2}$ max had lower Bacteroides, but higher Eubacterium rectale-Clostridium coccoides than the high $\mathrm{VO}_{2} \mathrm{max}$ group. Aerobic capacity was inversely associated with Eubacterium rectale-Clostridium coccoides but not with other bacteria. After adjusting for age and dietary intake, all significant associations remained.

In professional rugby players, who had a unique dietary pattern (higher energy intake and quantities of protein, fat, carbohydrates, sugar and saturated fat per day, with protein accounting for considerably more of the total energy) and a high level of physical activity, there was a higher diversity of gut microbiota compared with controls [19]. However, it was unclear if this effect was due to exercise, a high-protein diet, a combination of these two factors, or other factors [19].

\section{Acute exercise effects on the human gut microbiota}

To investigate the effect of an acute exercise bout in athletes, Zhao et al. [20] examined the fecal metabolites and microbiota in 20 amateur runners before and after a half-marathon race using metabolomics and 16S rRNA sequencing analysis. According to the alpha diversity analysis, there were few differences in diversity, nevertheless, abundances of certain microbiota members showed differences before and after running. At the phylum level, Lentisphaerae and Acidobacteria, whose functions in the human gut are unknown, were detected after running. At the species level there was a marked increase in the families Coriobacteriaceae and Succinivibrionaceae. Coriobacteriaceae (phylum Actinobacteria) is involved in metabolism of bile salts and steroid hormones as well as activation of dietary polyphenols in the human gut [95]. Coriobacteriaceae was correlated positively with 15 metabolites, indicating that metabolism of Coriobacteriaceae may be a potential mechanism underlying the role of exercise in preventing disease and improving health outcomes. These increased metabolites indicate a microbiota-derived metabolism was promoted by running. At the genus level, half-marathon running reduced the abundance of fecal Ezakiella, Romboutsia, and Actinobacillus, but increased the abundance of Coprococcus and Ruminococcus bicirculans. Actinobacillus species are purportedly responsible for several distinct animal diseases, such as actinomycosis in cattle, potent septicemia in the neonatal foal, and human periodontal disease [96]. Thus, inhibition of this potential pathogen indicated an anti-inflammatory effect of exercise. Interestingly, the pentose phosphate pathway, a metabolic pathway parallel to glycolysis and involving the oxidation of glucose, was the most enriched pathway after a half-marathon run. These findings highlight a microbiota-derived mechanism for the health-promoting benefits of exercise.
In a unique study by Scheiman et al. [16], athletes who were to run the Boston Marathon were recruited, along with a set of sedentary controls to identify gut bacteria associated with athletic performance and recovery states. $16 \mathrm{~S}$ ribosomal DNA sequencing was conducted on daily fecal samples collected up to 1 week before and 1 week after the marathon event. The relative abundance of the bacterial genus Veillonella increased after the marathon and was the most differentially abundant microbial feature between the pre- and post-exercise states. Additionally, Veillonella was more prevalent among runners compared to non-runners. Veillonella species metabolize lactate into the SCFA acetate and propionate via the methylmalonyl-CoA pathway [97]. To replicate these results in a second experiment and an additional cohort of human athletes, Scheiman and colleagues [16] performed shotgun metagenomic sequencing on stool samples from ultramarathoners and Olympic trial rowers both before and after an exercise bout. Similar findings were reproduced as relative taxonomic abundances Veillonella were increased post-exercise. In addition, the Veillonella methylmalonyl-CoA pathway was overrepresented in the metagenomic samples post-exercise across the cohort. Given the limited prevalence of the methylmalonyl-CoA pathway across lactate-utilizing microbes, this enrichment post-exercise may implicate Veillonella in causing functional changes in the metabolic repertoire of the gut microbiota. It seems that the genus Veillonella is enriched in athletes after exercise and the metabolic pathway that Veillonella species utilize for lactate metabolism is also enriched. Gut colonization of Veillonella may augment the Cori cycle by providing an alternative lactate-processing method whereby systemic lactate is converted into SCFAs that re-enter the circulation. Higher levels of lactic acid in athletes' GI tract favor the growth of this genus and these bacteria may in turn produce a compound that could aid performance.

In a third set of experiments, Scheiman et al. [16] isolated a strain of Veillonella atypica from a stool sample of one of the aforementioned marathon runners and inoculated mice. In a pre-clinical crossover trial, Veillonella inoculated mice had a $13 \%$ improvement in time to exhaustion running tests as well as significant reductions in inflammatory cytokines post exercise compared to control. They also more effectively converted lactate to the SCFAs propionate. Importantly, Scheiman et al. [16] found systemic lactate in these animals was able to cross the gut barrier into the lumen, making it available as a substrate for microbial SCFA conversion. Taken together, these experiments revealed that $V$. atypica improved run time via its metabolic conversion of exercise-induced lactate into propionate, thereby identifying a natural, 
microbiome-encoded enzymatic process that enhances athletic performance. While other studies reported butyrate as a prominent feature of the athletic microbiota [13, 14, 72, 88, 98, 99], this research implicated propionate as another significant beneficial SCFA. Moreover, these preclinical, proof-of-concept experiments displayed for the first time that beneficial microbes from athletes can be effectively transferred to enhance performance. While performed in animal model, this research is notable as it took an important step from correlative to causal function, implicating athlete microbiomes for broader human health and performance applications.

\section{Chronic exercise effects on the human gut microbiota}

In a longitudinal research design, Allen et al. [98] reported for the first time that exercise training can modulate the composition and metabolic capacity of the human gut microbiota in previously sedentary individuals. Lean and obese subjects underwent 6 weeks of endurance training with diet controlled, followed by a 6-week washout period [98]. Exerciseinduced modulations of the gut microbiota and SCFA were strongly associated with changes in body composition in lean participants and $\mathrm{VO}_{2} \max$ in obese participants, independent of diet. After the washout period, exercise-induced changes in the microbiota were largely reversed once exercise training ceased. This study supports the notion that gut microbiota composition is linked to exercise status and that exercised-induced changes may be temporary and require continual stimulus [100]. Of note, the exercise induced shifts in SCFA-producing taxa (Faecalibacterium species [spp.] and Lachnospira spp.) and genetic machinery (butyrate-regulating gene, BCoAT) were more substantial in lean versus obese participants. This connection is also supported by the observed shifts in metabolic capacity of the gut microbiota which may be transient and likely dependent on repeated exercise stimuli.

Taniguchi et al. [101] evaluated whether endurance exercise modulates the gut microbiota in elderly subjects, and whether these changes are associated with host cardiometabolic phenotypes. In a randomized crossover trial, 33 elderly Japanese men participated in a 5-week endurance exercise program. 16S rRNA gene-based metagenomic analyses revealed that the effect of endurance exercise on gut microbiota diversity was not greater than interindividual differences, whereas changes in alpha diversity indices during intervention were negatively correlated with changes in systolic and diastolic blood pressure, especially during exercise. Microbial composition analyses showed that the relative abundance of Clostridioides difficile decreased, whereas that of Oscillospira increased during exercise compared to the control period. The changes in these taxa were correlated with the changes in several cardiometabolic risk factors. These findings indicate that the changes in gut microbiota were associated with cardiometabolic risk factors, such as systolic and diastolic blood pressure. It appears microbial SCFAs influence blood pressure by interacting with host SCFA receptors [102]. In another study with elderly subjects, Morita et al. [103] examined the effect of a 12-week exercise intervention on the composition of intestinal microbiota in healthy women. The relative abundance of intestinal Bacteroides increased in subjects that completed aerobic exercise. In addition, the increases in Bacteroides following the exercise intervention were positively associated with increases in a 6-min walk test. It is widely accepted that lower levels of Bacteroides are associated with the higher prevalence of obesity and metabolic syndrome and that Bacteroides species may help in suppressing metabolic dysfunction [79, 104]. However, Bacteroides sometimes correlate with higher BMI and a Westernized diet [105]; therefore, the increased relative abundance observed after the 12-week exercise intervention may be due to its ability to shift substrates compared to other taxa that more reproducibly decline with a high-fat diet (i.e., Bifidobacteria).

More recently, Liu et al. [106] conducted a wellcontrolled exercise intervention in 39 prediabetic, medication-naive overweight men with a comprehensive metagenomics and metabolomics analysis. Subjects maintained their normal dietary routine and were randomized into either a control group (no exercise; $n=19$ ) or a supervised high-intensity exercise program $(n=20)$ consisting of $70 \mathrm{~min}$ combined aerobic and resistance interval training 3 times per week. Despite the overall metabolic benefits of the intervention, $\sim 30 \%$ of subjects responded poorly to exercise in terms of improvement in glycemic control and insulin sensitivity. Those that did respond showed a remarkable decrease in fasting insulin and Homeostatic Model Assessment of Insulin Resistance index values $(-42.70 \%$ and $-49.60 \%$, respectively). Upon investigating the gut microbiota there was a clear segregation in compositional and functional changes between exercise responders and non-responders, accompanied by distinct alterations in microbial metabolites. Specifically. responders displayed greater gene expression of functional pathways generating SCFAs and breaking down BCAAs. These may have been related to the positive findings in glucose metabolism as the rise of BCAA has been associated with insulin resistance [107]. There was also a trend in changes of the metabolites of amino-acid catabolism (BCAAs and 
aromatic amino acids) and carbohydrate fermentation that was consistent with the altered patterns of genes encoding for associated metabolic enzymes. Conversely the microbial profiles of non-responders after the exercise intervention shared more similarity with those of the sedentary controls, suggesting a maladaptation of gut microbiota in these individuals. Similar to the findings from Barton et al. [13] in professional rugby athletes, pathways involved in DNA replication and amino acid metabolism were preferentially enhanced in responders. Moreover, genes related to glycan biosynthesis and lipid metabolism were elevated in responders. Although there was no obvious difference in baseline microbial structures between responders and non-responders, Liu and colleagues were able to establish a model based on a machinelearning algorithm from baseline microbiome signatures which accurately predicted the exercise outcomes with respect to glycemic control and insulin sensitivity. This raised the possibility of screening for individuals with high likelihood of exercise resistance using gut microbiota, so that personalized adjustments can be implemented in time to maximize the efficacy of exercise intervention.

To examine the potential causal relationship between the differentially shaped microbiotas, Liu et al. [106] then transplanted conventional antibiotictreated mice with the microbiota from two responders and two non-responders from the above experiment. A substantial improvement in mice gavaged with microbiota from responders was mimicked in glycemic control and insulin sensitivity, in contrast to the lack of change in mice colonized with microbiota from non-responders. Together, the results from both the human and animal studies indicate that exercise may impose a differential impact on the composition and function of the gut microbiota across individuals. While future research is warranted, this study raised the possibility that the makeup of the gut microbiota may be a determiner for the efficacy of exercise (i.e., responders vs non-responders) and that targeting the gut microbiota could maximize the benefit of exercise. It may have been that exercise amplified subtle differences of the gut microbiota at baseline by remodeling the intestinal microenvironment (such as inflammatory and oxidative status and local immunity) critical for microbial growth and interaction, which ultimately lead to a divergent response of glycemic control to exercise intervention. Finally, these findings further reinforce the notion that the functional capacity of gut microbiota, as assessed by metagenomics and metabolomics, can be significantly altered without major shifts in its community structure, and that changes in host phenotype may be more dependent on the metabolic capacity and metabolites of the microbiota, instead of the composition per se.

In the longest exercise intervention to date, Kern et al. [108] investigated the effects of regular aerobic training of different intensities and modalities with similar exercise energy expenditure on gut microbiota over a 6-month period. A total of 88 sedentary overweight/obese subjects were randomized into four arms, including habitual living (control), active commuting by non-motorized bicycle, leisure-time exercise of moderate intensity, or vigorous intensity exercise. Beta diversity changed in all exercise groups compared to control, with participants in the vigorous intensity group showing decreased heterogeneity. Further, the vigorous exercise group experienced a greater increase in alpha diversity at 3 months compared to control. More intense exercise may be needed to induce change in the gut microbiota in sedentary, overweight/obese subjects. In a study of acute exercise, both high intensity interval and moderate continuous training affected the gut microbiota in insulin resistant, sedentary individuals following a 2-week exercise intervention [109]. Specifically, Bacteroidetes increased and the Firmicutes/Bacteroidetes ratio decreased. This outcome has relevance to athletes as the increase in Bacteroidetes plays an essential role in the metabolic conversions of complex sugar polymers and degradation of proteins [110]. There was also a decrease in Clostridium and Blautia genera. Clostridium plays an important role in wholebody immune responses, while Blautia purportedly increases the release of proinflammatory cytokines [111]. Interestingly, colonic glucose concentrations associated positively with Bacteroidetes and inversely with Firmicutes phylum, the Firmicutes/Bacteroidetes ratio, and Blautia genus. In addition, lower abundance of Blautia genus was associated with better whole-body insulin sensitivity. These results highlight the importance of intestinal substrate uptake on the whole-body and changes, especially in glucose uptake, might have a positive effect on the gut microbiota.

Finally, in an observational study, Keohane et al. [99] explored the gut microbiota response of four welltrained ultra-endurance male athletes to prolonged, high intensity trans-oceanic rowing, describing changes in microbial diversity, abundance, and metabolic capacity. Serial stool samples were obtained from the athletes for metagenomic whole-genome shotgun sequencing to record microbial community structure and relevant functional gene profiles pre-race, mid-race, race-finish, and 3 months post-race after a continuous, unsupported 33day, $5000-\mathrm{km}$ transoceanic rowing event. Alpha diversity increased throughout the ultra-endurance event and was evident as early as day 17 in the race. This increase 
occurred independent of any change in cardiorespiratory fitness, with $\mathrm{VO}_{2} \max$ similar pre- and post-race. Variations in taxonomic composition included increased abundance of butyrate producing species and species associated with improved metabolic health and improved insulin sensitivity.

The functional potential of bacterial species involved in specific amino and fatty acid biosynthesis also increased. Specifically, the gene expression of functional metabolic pathways involved in L-isoleucine and Llysine production increased, which play an important role in reducing muscular fatigue and damage during strenuous exercise [112]. Microbial-derived lysine may also contribute to the body protein pool in humans [113]. Changes in essential amino acid availability influence hematopoiesis, which in turn may increase oxygen carrying capacity and cardiorespiratory fitness [112]. Many of the adaptations in microbial community structure and metaproteomics persisted at 3 months follow up.

\section{Summary of the effect of exercise on the gut microbiota}

Overall, the mechanisms by which physical activity may promote a rich bacterial community and increased functional pathways have not been fully elucidated but likely involve a combination of intrinsic and extrinsic factors. For example, physically active individuals are more likely to be exposed to their environmental biosphere (e.g., time spent outdoors) and follow an overall healthy lifestyle and, consequently, harbor a richer microbiota. Simultaneously, intrinsic adaptations to endurance training, such as decreased blood flow, tissue hypoxia, and increased transit and absorptive capacity can lead to changes in the GI tract $[114,115]$. Changes in GI transit time have been reported to affect the $\mathrm{pH}$ within the colonic lumen which could lead to alterations in the composition of the gut microbiota. For instance, longer colonic transit time is associated with decreased gut microbiota diversity, which is paralleled by an increase in $\mathrm{pH}$ during transit from the proximal to the distal colon $[116,117]$. Repeated bouts of aerobic exercise can increase GI transit time in healthy individuals and middle-aged patients with chronic constipation [118-120]. However, at higher intensities (e.g., above $70 \% \mathrm{VO}_{2} \max$ ), gastric emptying appears to be delayed [121-124]. Aerobic exercise also increases fecal SCFA concentration which can decrease $\mathrm{pH}$ in the colonic lumen [125]. Furthermore, metabolites that are a by-product of exercise and circulate throughout the body (e.g., lactate) may filter through the gut and serve as an energy source for certain bacterial taxa (e.g., Veillonella). There is expected competition for nutrients and resources in every ecosystem, including the gut microbiota. Therefore, many of these microbial characteristics may be a result of 'form fits function', as communities in the gut are shaped by available resources, as determined by the physiology of their host. These and other potential adaptive mechanisms, such as a change in gut $\mathrm{pH}$, may create an environmental setting that allows for richer community diversity and metabolic functions. Anaerobic capacity and resistance exercise training may also influence community composition, though to date, no work has examined these parameters in relation to gut microbiota.

A single acute bout of prolonged excessive exercise can have a deleterious influence on intestinal function. Intense exercise redistributes blood from the splanchnic circulation to actively respiring tissues [126]. Prolonged intestinal hypo-perfusion impairs mucosal homeostasis and causes enterocyte injury. Intestinal ischemia may result, particularly in the setting of dehydration, manifesting as abdominal cramps, diarrhea, or occasionally bloody diarrhea [127]. This adverse effect is particularly the case in endurance sports [128]. As a result, increased intestinal permeability ensues, thought to be driven by the phosphorylation of several tight junction proteins [129]. These events render the gut mucosa susceptible to endotoxin translocation [130]. Moderate endurance exercise in mice has been associated with a lesser degree of intestinal permeability, preservation of mucous thickness, and lower rates of bacterial translocation along with up-regulated anti-microbial protein production and gene expression in small intestinal tissue ( $\alpha$-defensin, $\beta$-defensin, Reg IIIb and Reg IIIc) [131]. Together these changes might help mitigate the effects of stress-induced intestinal barrier dysfunction. In humans, physical activity can improve gastrointestinal symptoms in subjects with irritable bowel syndrome [132]. Collectively, these outcomes are evidence of a differential and dose-response effect of exercise on gut health, with the underlying mechanisms yet to be fully explored in healthy humans.

The current body of research supports the role of exercise as an important behavioral factor that can affect qualitative and quantitative changes in the gut microbial composition and function with benefits to the host. Although these changes may not occur in a similar fashion across individuals and may also depend on baseline characteristics of both the microbiota and host. However, based on the current body of research, exercise appears to enrich microbiota diversity, stimulate the proliferation of bacteria which can modulate mucosal immunity, improve barrier functions, and stimulate bacteria and functional pathways capable of producing substances that protect against gastrointestinal disorders and 
improve performance (i.e., SCFAs). Indeed, exercise may be an important intervention to alter gut microbiota composition and restore gut symbiosis [100]. However, excessive and/or prolonged highintensity exercise may not impart these effects. Notably, certain taxa may be enriched in athletes such as the lean phenotype-associated A. muciniphila, and propionate producing Veillonella (via metabolism of lactate). In addition, higher diversity of microbiota composition was associated with lean phenotypes compared to that of obese individuals. It is likely that the diverse, metabolically favorable intestinal microbiota evident in the elite athlete is the cumulative manifestation of many years of high nutrient intake and high degrees of physical activity and training throughout youth, adolescence, and during adult participation in high-level sports [133]. Future areas of gut microbiota research in relation to athletes and exercise is presented in Table 3.

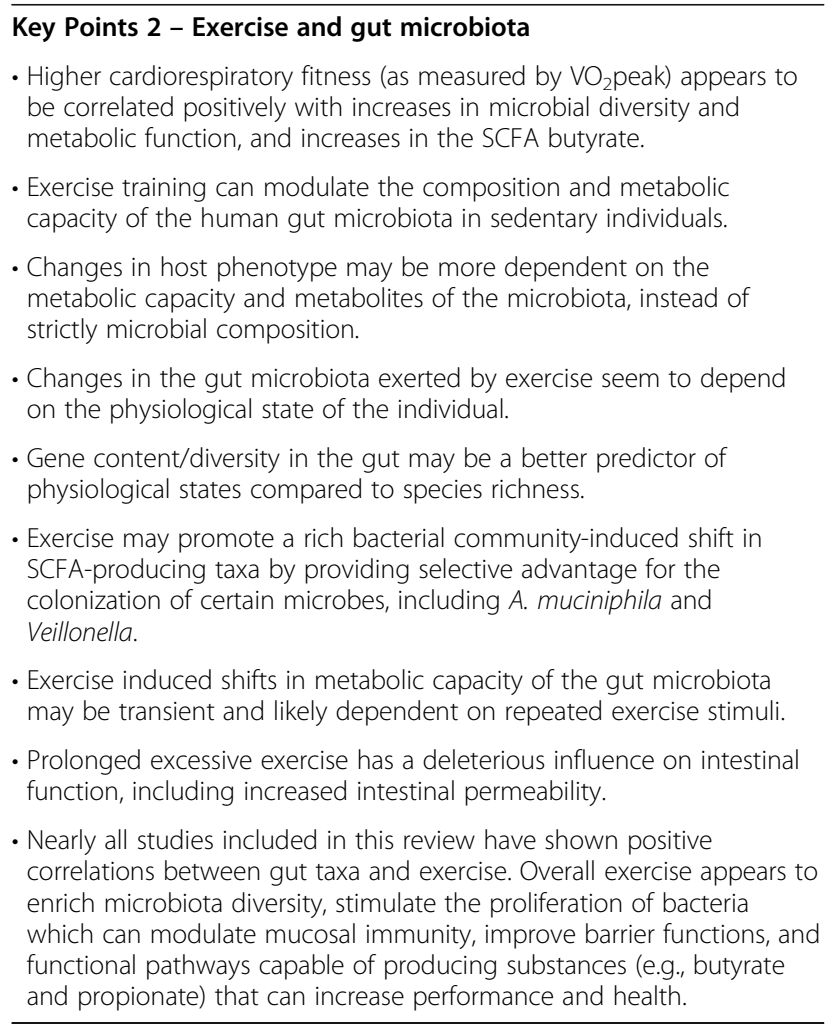

\section{The effect of athletic diet on the gut microbiota}

In researching the human gut microbiota, it is difficult to examine exercise and diet separately. This relationship is compounded by changes in dietary intakes often associated with physical activity (e.g., increased protein intake in resistance trained athletes or carbohydrate intake in endurance athletes and increased total energy and nutrient intake in general). Athletes often consume a diet that differs from the general population with implications on the composition of the gut microbiome.

Diet is an established modulator of gut microbiota composition, with significant alterations reported within $24 \mathrm{~h}$ of a dietary change [134]. This ability to rapidly change has implications in research design for the timing of measurements in exercise studies, as does dietary composition. Indeed, various food components, dietary patterns, and nutrients all have the potential to substantially alter the growth of different gut microbial populations. Medication and diet are principal environmental factors that influence gut microbiota composition according to large-cohort studies [135, 136]. The gut microbiota is an important factor that shapes both energy harvest and storage through metabolism of proteins and production of several metabolites including SCFAs, ammonia, sulfur-containing metabolites such as hydrogen sulfide and methanethiol, and neuroactive compounds such as tryptamine, serotonin, phenethylamine, tryptophan, and histamine [137, 138]. Moreover, the gut microbiota can also synthesize de novo amino acids and is involved in the utilization and catabolism of several amino acids originating from both alimentary and endogenous proteins. These amino acids can serve as precursors for the synthesis of other metabolites produced by the microbiota including SCFAs [139]. Animal studies have revealed communication between the gut microbiota and muscle, in which gut microbiota can affect muscle energy homeostasis by interfering with fat deposition, and lipid and glucose metabolism through various metabolites including SCFAs and secondary bile salts [17]. Broadly, athletes consume higher energy diets compared to sedentary individuals and are often encouraged to consume a diet high in carbohydrate and protein and lower in fat [140]. During training and competition, fiber intake may be reduced to avoid potential GI issues including gas and distension [141]. Importantly athletes' dietary plans often account for macro- and micronutrient needs, hydration, the timing of nutrients, and dietary supplements, but rarely is the health of the gut microbiota considered [140]. Here we describe the influence of total energy intake and the principal macronutrient classes (protein, carbohydrate, and fat) on the gut microbiota.

\section{Energy intake}

The GI tract represents the interface between ingested nutrients and the host where energy is effectively extracted. In healthy adults, $~ 85 \%$ of carbohydrates, $65-$ $95 \%$ of proteins, and nearly all fats are absorbed before entering the large intestine [142]. Consequently, indigestible carbohydrates and proteins that enter the 
Table 3 Future areas of gut microbiota research in relation to athletes and exercise

Current gaps in knowledge:
1. Athletic-focused studies have assessed the taxonomic composition of
the gut microbiota, while placing less emphasis on functional capacity.

2. At present it is unclear how exercise affects the gut microbiota over long durations (i.e., > 6 months).

3. Little research is available directly comparing the potential differences in the gut microbiota between athletic disciplines, exercise routines, training loads, and physical fitness status.

4. There is limited research on how environmental factors affect the gut microbiota in athletes.

5. There is limited research available on how intrinsic adaptations to exercise impact the gut microbiota.

6. Some research is available showing prolonged excessive exercise has a detrimental influence on intestinal function.

7. Currently the gut-brain axis remains generally unexplored in athletes.

8. Currently the role of Akkermansia muciniphilia has not been fully elucidated in humans, although appears to be more present in athletes compared to non-athletes.

9. In relation to obesity, some athletes who may be defined as physically active using common criterion may not necessarily be healthier based on $\mathrm{BMI}$. There is limited research comparing these athletes to sedentary individuals matched for BMI.

10. The influence of energy stores (obese or lean state) and energy intake (positive or negative energy balance) on ability to alter the gut microbiota remain unclear.

11. The functional capacity of the athletic gut microbiota is not fully understood, particularly the relationship to the significant energy demands and tissue adaptation that occurs during intense exercise and elite sport.

12. Few studies have focused on the impact that voluntary exercise has on gut microbiota.

13. Some animal research reported exercise induces more effective changes in the microbiota in juvenile rats compared to adult rats.

14. Currently a few preclinical experiments have shown that beneficial microbes from athletes can be effectively transferred to enhance performance.

15. Limited research has shown that exercise-induced gut microbiota changes may be temporary and require continual stimulus.

16. Limited research has reported a segregation in compositional and functional changes between exercise responders and non-responders, accompanied by distinct alterations in microbial metabolites.

17. To date, no study in athletes has addressed RED-S syndrome in relation to the gut microbiota. Moreover, little is known on the effects of energy reduced diets in athletes looking to healthfully reduce bodyweight and/or improve body composition.
Recommendation(s) for future studies to address:

- The functional capacity of gut microbiota, as assessed by metagenomics and other omic-driven techniques (e.g., metabolomics), can be significantly altered without major shifts in community structure. Effects on the host may be more dependent on the metabolic capacity and metabolites of the microbiota, instead of the composition per se. Therefore, investigators should incorporate functional assessment of the gut microbiota.

- Assess the effect of exercise on the gut microbiota, as well as the gut microbiota in athletes over longer periods of time.

- Examine the potential differences in the gut microbiota between these factors in both cross-sectional and longitudinal investigations.

- Explore the effect of temperature, humidity, pollen/allergens, and other relevant environmental factors in relation to the gut microbiota in athletes.

- Investigate how such factors as decreased blood flow, tissue hypoxia, and increased/decreased transit and absorptive capacity in the Gl tract can lead to changes in the gut microbiota.

- Investigate how prolonged, excessive exercise impacts intestinal function (i.e., increased intestinal permeability) and the gut microbiota.

- Explore the gut-brain axis in athletes, as well as the impact of exercise in sedentary individuals.

- Continue to investigate the role Akkermansia muciniphilia plays in the gut microbiota and its functional impact on metabolism.

- Investigate this comparison at the obese classification. Findings from this research could provide important data in connection with the pathogenesis of obesity and the gut microbiota.

- Gut microbiota research in athletes with high, as well as low energy consumption requires further investigation.

- Research in those implementing caloric reduction with exercise for weight loss is also needed.

- Intervention-based studies should be conducted to further delineate this relationship.

- Results from such research will be important and may provide further insights into optimal therapies to influence the gut microbiota, and its relationship with health and disease as well as athletic performance.

- More animal research should be conducted looking at the difference between forced vs. voluntary exercise in relation to exercise volume.

- Research in animal models, as well as humans, should examine the effect of exercise on the gut microbiota comparing different age classifications.

- Research in animal models should continue to test the functions of these microbes expressed in athletes (e.g, Veillonella) and explore their implications for broader human health and performance applications.

- More research is needed investigating the temporal effect of exercise stimuli on the gut microbiota and its functional capacity, both at the acute and chronic level.

- Replication of these findings and further investigation of the possibility that the makeup of the gut microbiota may be a determiner for the efficacy of exercise (i.e., exercise responders vs non-responders)

- Explore the possibility of targeting the gut microbiota of 'nonresponders' to increase the benefit of exercise.

- Dissect the impact of restricted energy consumption and/or increased energy expenditure on the gut microbiota in athletes.

18. The effects of high-protein (without concurrent high-fat) consumption • Investigate the effect of higher protein consumption on the gut 
Table 3 Future areas of gut microbiota research in relation to athletes and exercise (Continued)

Current gaps in knowledge: ${ }^{\text {a }}$
high-protein and high-fiber intake.

19. Protein intake appears to be a strong modulator of gut microbiota diversity, however there is little research examining the effect of protein supplementation.

20. Early research has reported changes in the gut virome from protein supplementation, suggesting virus particles from whey protein transmit to the gut from consumption.

21. The genus Prevotella has been reported to be positively associated with both health and disease states.

22. Little is known about exercise-nutrient interactions that underpin adaptation and performance.
Recommendation(s) for future studies to address:

microbiota, particularly in the context of lower fat and higher fiber intakes.

- The types and amounts of fats consumed in conjunction with protein should be investigated in the overall effect on the gut microbiota.

- Examination of the effect of prebiotics and probiotics in conjunction with increased protein intake.

- More research needs to be conducted investigating the effect of protein supplementation, such as whey and vegetable-based proteins, on the gut microbiota.

- The effect of the gut virome on the gut microbiota and host requires further investigation, particularly in relation to food and supplement consumption.

- More studies in humans are needed to better understand Prevotella's role in athletes, as well as its role in disease. For this, more in-depth metagenomic studies will be required to reveal the health- or diseasemodulating properties of Prevotella, particularly at species and functional level.

- Further research is needed to determine the synthesis kinetics and clinical consequence of microbial by-products during increased nutritional status and metabolic demands during exercise.

- Determine if specific nutrient recommendations aimed at improving performance can be made by enhancing certain metabolites during exercise and recovery. This includes limiting those that produce toxic metabolites that may worsen the consequences of exercise stress.

\footnotetext{
${ }^{a}$ Gaps observed in studies from the current review
}

${ }^{b}$ Relative Energy Deficiency in Sports

colon represent between 10 and 30\% of total ingested energy [143, 144]. If not for the colonic microbiota, these nutrients would generally be eliminated via the stool without further absorption due to the limited digestive capability of the human large intestine [142]. Therefore, the gut microbiota plays an important role in energy extraction and, in turn, can be influenced by the composition of the diet and the amount of energy entering this environment [145]. In relation, the gut microbiota produces and releases an enormous array of compounds which may act upon host tissues modulating appetite, gut motility, energy uptake and storage, and energy expenditure [146, 147]. Riedl et al. [148] estimated that for an average $90 \mathrm{~kg}$ male, the biomass of bacteria in the gut could be expected to contribute anywhere from 7 to $22 \%$ of daily adult human caloric turnover (based on $2000 \mathrm{kcal}$ [kcal] per day). Clearly, the gut microbiota-host interaction can affect energy balance which has implications for weight gain or loss and body composition [149, 150].

Strong evidence exists to support the role for the gut microbiota in energy balance by contributing to host digestive efficiency [151]. Studies of lean and obese mice indicate that the gut microbiota affects energy balance by influencing the efficiency of calorie harvest from the diet and how this harvested energy is used and stored. For example, studies of germ-free mice (so called 'gnotobiotic mice') have provided important insights into the role the gut microbiota plays in energy homeostasis. Gnotobiotic mice are inefficient at processing food, yet when colonized with conventional mouse gut biota they gain weight by increasing their energy stores [152]. This weight gain occurs even when decreasing energy intake by $30 \%$ and increasing energy expenditure by $30 \%$, compared to mice who remained germ-free [153]. These results implicate the gut microbiota as an energy harvester, significantly affecting nutrient absorption by extracting energy from dietary substances.

To examine the impact of energy consumption on the gut microbiota, rats fed a high-energy dense diet rapidly altered their gut microbiota with increases in Firmicutes/Bacteroidetes ratio and in pro-inflammatory Proteobacteria proliferation compared to those consuming a low-energy diet [154]. Moreover, the high-energy diet increased circulating pro-inflammatory LPS. However, the impact of energy consumption on, and the ultimate extraction by, the gut microbiota is deeply intertwined with composition of the ingested diet. For example, obese mice fed a low saturated fat, high fruit and vegetable diet can take on microbiota characteristics of lean mice [63]. Moreover, mice consuming this diet regardless of lean or obese state gained less fat mass compared to lean and obese mice fed a high-saturated fat, low fruit and vegetable diet, typical of a Westernized diet.

In terms of human research there are few studies that have examined the effect of energy intake and energy 
expenditure on the gut microbiota. The majority of this research has been conducted in relation to the study of obesity, weight loss, and malnourishment in children. Generally, when comparing obese and lean individuals, both the diversity of the gut microbiota and the ratio of Bacteroidetes to Firmicutes is decreased in obese individuals [145]. Similar findings have been reported in relation to gene richness and altered metabolic pathways [155]. However, the composition of the gut microbiota does appear to be sensitive to caloric balance as noted in subjects studied before, during, and after weight loss [38]. Furthermore, improved gene richness has been reported during weight-loss and weight-stabilization interventions in obese and overweight individuals [156]. What remains unclear is the influence of energy stores (obese or lean state) versus the impact of energy intake (positive or negative energy balance) on ability to alter the gut microbiota. In a carefully monitored inpatient crossover feeding trial, Jumpetz and colleagues [157] examined how gut bacterial community structure is affected by two distinct caloric loads $(2400 \mathrm{vs} 3400 \mathrm{kcal} /$ day) with a similar nutrient profile (24\% protein, $16 \%$ fat, and 60\% carbohydrates) and dietary energy harvest in 12 lean and 9 obese individuals. The higher caloric load was positively correlated with the relative abundance of Firmicutes species and negatively correlated with the relative abundance of Bacteroidetes species in both lean and obese humans. In lean individuals, these changes were associated with an increased energy harvest of approximately $150 \mathrm{kcal}$. This finding suggests that the microbiota is responsive to energy balance (degree of overfeeding) as well as actual adiposity. It may be that the gut "senses" alterations in nutrient availability and subsequently modulated the nutrient absorption. Regardless, these results show that the nutrient load is a key variable that can influence the gut community structure. In rugby athletes with high energy consumption (median intake of $4449 \mathrm{kcals}$ per day), gut microbial diversity was significantly greater compared to age and BMI matched sedentary controls (median intake of 2801 kcal per day) [19]. Moreover, in cyclists consuming high-energy, high-carbohydrate diets, abundances of health associated bacteria were high (including Prevotella and Akkermansia) and less characteristic of Western-associated microbiota [18]. However, it is difficult to remove physical activity influence from this, and gut microbiota research in athletes with high energy consumption requires further investigation.

In contrast to high-energy intake and obesity, even less is known about the gut microbiota in undernutrition [142]. Athletes can have a tremendous energy expenditure often requiring a corresponding increase in dietary intake to maintain energy balance. However, Relative Energy Deficiency in Sports (RED-S) syndrome is present in many athletic disciplines as a result of insufficient energy availability due to insufficient caloric intake and/or excessive energy expenditure [158]. Occurring in both males and females, RED-S possesses a significant health risk. To date, no study in athletes has addressed RED-S in relation to the gut microbiota. Moreover, little is known on the effects of energy reduced diets in athletes looking to healthfully reduce bodyweight and/or improve body composition. Calorie restriction, primarily in animals, can improve the composition and associated metabolism of the gut microbiota, including increasing the relative abundances of probiotic and butyrateproducing microbes [159] and increasing SCFA biosynthesis [160].

In humans, severe calorie restriction as a result of bariatric surgery offers an interesting research model to explore the effect on the gut microbiota [161]. Changes such as reduced abundance of Firmicutes post-surgery have been reported [162]. Although it is unclear if these modifications were caused by dietary change or weight loss. Furet and colleagues [163] reported that the Bacteroides/Prevotella ratio increased within 3 months after surgery and remained stable thereafter. While this ratio was negatively correlated with body weight, BMI, and body fat mass, the correlation was highly dependent on total calorie intake. Other alterations, such as the reduction of lactic acid forming bacteria, indicate a complex effect of severe calorie restriction.

Undernourished children have been observed to exhibit impaired gut microbiota development, with reduced relative abundance of several Bifidobacterium and Lactobacillus spp. as well as obligate anaerobic SCFA-producing taxa [164]. For instance, a sample of children living in an urban slum in Bangladesh with either moderate acute malnutrition or severe acute malnutrition had a gut microbiota that was 'immature'; meaning discriminatory taxa in their gut communities were more similar to younger rather than age-matched healthy individuals from the same location [165]. This 'immaturity' was greater in those more severely malnourished with probable physiologic, metabolic, and immunologic consequences [165]. This has led to the proposal that disrupted microbiota development impairs healthy bone and muscle growth during infancy [166]. To explore the association between nutrition and the gut microbiota during infancy, Charbonneau et al. [166] colonized young germ-free mice with the fecal microbiota of a growth-stunted Malawian infant. These animals were fed a representative Malawian diet with or without a bioactive substance in breast milk (purified sialylated bovine milk oligosaccharides). Treatment with the milk oligosaccharides produced microbiotadependent growth promotion, including lean body mass gain, changed bone morphology, and altered liver, 
muscle and brain metabolism. These effects were also documented in gnotobiotic piglets using a similar design showing a greater ability to utilize nutrients from the diet [166]. These preclinical models indicate a causal, microbiota-dependent relationship between nutrition and growth promotion which may have implications for younger athletes.

Various studies have explored the gut microbiota of anorexia nervosa patients with the majority of them being characterized by heterogeneity in the methodology and small sample sizes (for review see: [167]). Several studies of anorexia nervosa patients have reported decreased abundances of the butyrate producing Roseburia in combination with reduced butyrate levels and lower microbial diversity and taxa abundance compared to healthy controls [168-170]. During an inpatient, medically supervised weight gain study in anorexic individuals, microbial richness increased, however perturbations in intestinal microbiota and SCFA profiles, in addition to several gastrointestinal symptoms, did not recover during the subject's in-patient stay [169]. Future studies will be needed to dissect the impact of restricted energy consumption and/or increased energy expenditure on the gut microbiota in athletes.

Overall, energy balance is an overlooked factor in relation to the athletic gut microbiota. Not only is this relevant to improving performance, but also addressing the health status of those affected by RED-S. Different dietary patterns affecting macronutrient consumption can alter the composition of what enters the large intestine where there is the greatest density of gut microbes. This has a tremendous impact on the human body's ability to extract and utilize energy from the diet. Moreover, it is difficult (if not impossible) to solely investigate the impact of total energy consumption on the composition of the gut microbiota without considering dietary variability such as the major dietary macronutrient classes.

\section{Protein}

Despite the difficulties of studying macronutrient effects in isolation, there is evidence to support the assertion that dietary protein (and fat) consumption elicit both compositional and functional changes to the gut microbiota [171]. David et al. [134] showed a rapid shift in gut microbial community composition and increased populations of Alistipes, Bilophila, and Bacteroides after consuming a high-fat/protein diet for 5 days and these changes were thought to be a result of increased bile secretion. Changes to the gut microbiota have also been documented when dietary protein is increased: Bacteroides spp. are highly associated with animal proteins, whereas Prevotella spp. are highly associated with increased intakes of plant proteins [172]. Intervention studies have demonstrated that high-protein diets (animal protein) reduced fecal butyrate concentrations and butyrate-producing bacteria such as Bifidobacteria spp., Roseburia spp., and E. rectale [173-175]. Fecal concentrations of potentially damaging $\mathrm{N}$-nitroso compounds increase markedly in volunteers who consumed a highprotein, low-carbohydrate diet [175]. Furthermore, a study of five male volunteers consuming high intakes of animal protein showed that fecal sulfide production is related to meat intake [176]; notably, hydrogen sulfide is a compound associated with ulcerative colitis [177]. Ma et al. [178] suggested that excessive protein intake or an unsuitable ratio of protein to protein-fermenting bacteria, could potentially produce adverse effects on health.

The partitioning of individuals into so-called 'enterotypes' (stratifying global microbiome variation into a few categories, reviewed in [179]) has been suggested to be driven by whether their primary dietary patterns include high complex carbohydrate (Prevotella) or highfat/protein (Bacteroides) consumption [172]. This categorization has been criticized as an oversimplification, obscuring potentially important microbial variation, and may not be appropriate for the athletic population $[180,181]$. For example, the Bacteroides enterotype has been suggested to most strongly be correlated with frequent consumption of animal protein and saturated fat. However, the effects of high-protein consumption (without concurrent high-fat) on gut bacteria are not well studied but of increasing importance given the current popularity of high-protein diets, especially in athletes. In professional rugby players, distinct compositional and functional microbial characteristics, including increased alpha diversity, enhanced microbial production of SCFAs, and greater metabolic capacity are evident in the gut $[13,19]$. These microbial features not only positively correlate with the athletes' levels of physical activity, but also the quantity of dietary protein consumed. In many athletic disciplines, as well as recreational exercise, protein supplementation (e.g., whey protein) provides a sizeable proportion of athletes' daily protein intake [19]. Clarke et al. [19] reported microbiota diversity indices correlated positively with protein intake and serum creatine kinase indicating that diet and exercise are both drivers of biodiversity in the gut. The protein and microbiota diversity relationship is further supported by a positive correlation between blood urea levels (a byproduct of diets rich in protein) and microbiota diversity [19]. In contrast, Jang et al. [11] reported that daily protein intake was negatively correlated with alpha diversity in distance runners. The inconsistency of these results compared to Clarke et al. [19] may relate to the nutritional status of the athletes. In addition, the study by Clarke and colleagues [19] met all of the recommended dietary intake requirements, while the athletes in the investigation by Jang et al. [11] had insufficient 
carbohydrate and dietary fiber intake (compared to standard macronutrient distribution ranges). It seems that high-protein diets may have a negative impact on gut microbiota diversity for athletes in endurance sports who consume lower amounts of energy, carbohydrates, and dietary fiber, while athletes in resistance sports that follow a high-protein, low-carbohydrate, and high-fat diet demonstrate a decrease in SCFA-producing commensal bacteria. Long-term diets have been linked to certain compositional clusters in the gut microbiota: protein and animal fat are associated with Bacteroides enrichment and simple carbohydrates with Prevotella enrichment [172]. Excessive fermentation of dietary protein in the GI tract is generally considered detrimental given the production of toxic by-products such as amines, phenols, indoles, thiols, and ammonia [182, 183]. In contrast, feeding of whey protein to mice attenuated some negative effects on the composition of the gut microbiota composition including increasing Lactobacillaceae/Lactobacillus and decreasing Clostridiaceae/Clostridium [184, 185]. Further, whey protein has been associated with reductions in body weight and increased insulin sensitivity in the past, and is frequently a major component of the athlete diet, particularly in strength and power sports $[186,187]$.

Estaki et al. [14], reported total protein intake was a major contributor to increased beta diversity (the ratio between regional and local species diversity) at each taxonomic rank tested in 39 healthy adults with varying cardiorespiratory fitness levels. A strong association was evident between protein intake and Bacteroides and, in particular, Ruminococcaceae and Lachnospiraceae, two of the most abundant families in human gut environments [188], in explaining community diversity. These saccharolytic organisms persist in fibrolytic gut communities and are considered an important component of a healthy gut microbiota, while their depletion has been observed in inflammatory bowel disease patients $[189,190]$.

In comparing athletes to both high and low BMI nonathlete controls, Barton et al. [13] reported a greater number of pathways correlating to specific macronutrients within the control participants suggesting a shift in the dynamics of varied metabolic functions. The impact of the athletes' increased protein intake compared to both control groups was evident in the metabolomic phenotyping results. Metabolites derived from dietary protein (trimethylamine $\mathrm{N}$-oxide, carnitines, trimethylamine, 3Carboxy-4-methyl-5-propyl-2-furanpropionic acid, and 3hydroxy-isovaleric acid), muscle turnover (creatine, 3methylhistidine, and L-valine), vitamins and recovery supplements (glutamine, lysine, 4-pyridoxic acid, and nicotinamide), as well as phenylacetylglutamine (a microbial conversion product of phenylalanine) were increased in athletes [191].
Investigating the gut microbiota of cyclists, Petersen et al. [18] reported an increased abundance of Prevotella which positively correlated with a number of amino acid and carbohydrate metabolism pathways, including BCAA metabolism. High levels of BCAAs (leucine, isoleucine, and valine) can attenuate exercise-induced muscle fatigue and promote muscle-protein synthesis [192]. While there is strong evidence showing that BCAAs do not enhance exercise performance [192, 193], they may reduce central fatigue [194] and attenuate muscle damage during prolonged exercise [195]. Since BCAAs are not produced by the human body and need to come from the diet, having a gut microbial community that contains Prevotella spp. to either synthesize BCAAs or alternatively influence other microbes to produce these amino acids would be highly beneficial to athletes who require a rapid recovery from intense exercise.

In cross-country runners, the effect of 10 weeks of protein supplementation ( $10 \mathrm{~g}$ whey isolate and $10 \mathrm{~g}$ beef hydrolysate per day) consumed daily decreased SCFAproducing bacteria while increasing bacteria with proteolytic activity in the microbiota without affecting SCFAs, ammonia, or fecal $\mathrm{pH}$ of endurance athletes [196]. The amount of additional dietary protein was small but yielded a significant $17 \%$ increase in dietary protein for these athletes. Specifically, protein supplementation increased the abundance of the Bacteroidetes phylum and decreased the presence of health-related taxa including Roseburia, Blautia, and B. longum. In contrast to Clarke et al. [19], no changes in compositional microbiota diversity were detected after the tenweek intervention, which may relate to the low percentage of protein intake. Increases in dietary protein can increase the amounts reaching the colon, where they are metabolized by colonic microbiota, leading to changes in microbiota populations and in microbial metabolites [178]. The difference between these two studies may also be due to differences in analyses, as Clarke et al. [19] only assessed the V4 region of the gene, while the present study used the V3 and V4 region (see Table 4). Balancing the protein/carbohydrate ratio with prebiotics when protein intake is elevated [197], or accompanying the intake of protein supplements with probiotics, could be future strategies to mitigate the observed or anticipated gut microbiota shift [198].

Cronin et al. [199] noted participants consuming whey protein daily experienced a marked alteration in the diversity of their gut virome (a collection of viruses that inhabits the gut environment and affect host cells as well as other commensal organisms [200]) following 8 weeks of oral supplementation. Sedentary subjects (predominantly overweight $>30 \%$ body fat) were divided into three groups of 30 
Table 4 Recommendations for future gut microbiota research in athletes and exercise interventions

\begin{tabular}{|c|c|}
\hline Observed weaknesses: & Recommendation(s): \\
\hline $\begin{array}{l}\text { 1. Current microbiota sequencing methods rely heavily on } 16 \mathrm{~S} \text { rRNA } \\
\text { amplicon-based methodology which detects up to genus level with min- } \\
\text { imal capability for species-level detection. }\end{array}$ & $\begin{array}{l}\text { - Investigators are encouraged to utilize other methodology, such as } \\
\text { shotgun metagenomics for its expanded taxonomic range, strain-level } \\
\text { resolution, and identification of other microorganisms (i.e., archaea, vi- } \\
\text { ruses, and fungi, etc.). } \\
\text { - Omic techniques, such as metatranscriptomics, metaproteomics, and } \\
\text { metabolomics, should be integrated with compositional data to provide } \\
\text { a 'functional' readout of the microbiome providing data on the } \\
\text { metabolic interplay between the host, diet, exercise, and the gut } \\
\text { microbiota. } \\
\text { - For targeted genomic approaches specific primers for quantitative PCR } \\
\text { can be effectively used. }\end{array}$ \\
\hline
\end{tabular}

2. Primer selection and hypervariable regions of 165 rRNA (i.e., V1-V9) influence the observed microbial community.

3. Several studies report less stringent inclusion/exclusion criteria and did not fully account/control for confounding variables.
- When using 165 rRNA amplicon-based sequencing it may be better to sequence a single variable region (V4 is mostly used in human gut microbiome studies) with reads that (almost) entirely overlap to reduce errors [235].

- When outlining participant criteria, investigators should pay particular attention to important factors that may confound results such as medication use (e.g., antibiotics, bile acid sequestrants, metformin, etc.), dietary supplement use (e.g., prebiotics and probiotics), age, sex, ethnicity, geographical location, etc.

- To control for confounding effects investigators should collect more detailed data on such factors as dietary intake, training history, level of physical fitness, gastrointestinal function (e.g., gastrointestinal symptoms rating scale [236]), fecal pH, fecal form (i.e., Bristol stool scale, [237]), etc.

4. The majority of studies in the present review did not report power and sample size calculations.

5. Several studies in the present review did not provide adequate detail on sample collection and processing. Both of these factors can significantly affect the analysis and ultimately the results of the study.

6. Similar to issue \#5, several reports did not provide adequate detail in regard to sample transportation and storage.

7. While not a weakness per se, feces is the only sample material used in the analyses of the gut microbiota from the studies included in this review.

8. The variation in microbial analysis across different studies can make comparing/contrasting study findings difficult.
- Many studies in this field are likely underpowered. Therefore, investigators are encouraged calculate and report sample size estimations when appropriate.

- While there is no one method, investigators should provide detail on these procedures and ensure these methods are the same across samples.

- Time that samples are held at room temperature should be greatly minimized (i.e., $<24 \mathrm{~h}$ without preservative) and kept consistent across samples $[238,239]$.

- Homogenization of the whole stool sample may provide a more uniform sample. This method has been shown to reduce the variation in both the amount of DNA extracted and the relative abundance of bacterial taxa [240].

- Investigators should provide detail on these procedures and ensure these methods are the same across samples.

- The gold standard for microbial storage is freezing samples at $-80^{\circ} \mathrm{C}$ [241].

- Investigators are encouraged to keep freeze-thaw cycles minimal as they affect reproducibility [242].

- Eventually, more in-depth mapping of microbial community structure and function along the length of the Gl tract and across gradients (i.e., from lumen to mucosa) should be considered [34].

- Variation in profiling techniques (e.g., sequencing strategies, platforms, variable regions, sequencing depth, etc.) may act as a confounding variable that can lead to significant differences due entirely to laboratory techniques rather than treatment. While a limitation of the current review, future, more specific reviews should provide deeper discussions on results in the frame of their methodological approaches. subjects: an exercise-only group, a daily whey protein supplementation ( $30 \mathrm{~g}$ per day) group, and an exercise plus daily whey protein supplementation $(30 \mathrm{~g}$ per day) group. Individuals in the whey protein supplementation-only group experienced a significant increase in the beta diversity of the gut virome. Furthermore, this change was mirrored in the combined exercise and protein supplementation group, suggesting a robust positive effect of whey protein on the taxonomic richness of the gut virome. Specifically, all bacteriophages (bacteria-targeting viruses) increased in the groups receiving whey protein were present in high relative abundance within the whey protein supplement. Therefore, it may be virus particles from 
whey protein transmit to the gut from consumption. The effect of the gut virome on the gut microbiota and host requires further investigation, particularly in relation to food and supplement consumption.

The source of protein, including its quality and digestibility, may influence the site of fermentation within the gut. Highly digestible proteins, such as whey, can be digested by host enzymes in the proximal intestine, reducing microbial fermentation. Similarly, plant-originated proteins are available for microbial fermentation in a more distal site given incomplete digestion by host enzymes, particularly at a higher protein level. Evidence indicates proteins from vegetable origin have a more marked effect on microbial diversity than animal proteins [201], however investigation in athletes is needed. By selecting dietary ingredients containing protein of rather high digestibility and quality, the amount of dietary protein reaching the large intestine may be diminished, thus limiting the quantity of residual protein available for protein fermenting bacteria. As a consequence, the growth and activity of potential pathogens could be suppressed. These seemingly opposing effects of high-protein diets imply that protein-diet interactions are modulated by factors such as host body composition and exercise intensity. The types and amounts of fats consumed in each of these studies are also likely important for the overall effects on the gut microbiota. For example, a ketogenic diet alters gut microbiota composition leading to an increase in Akkermansia abundance. Moreover, Akkermansia fed to mice has a positive impact on reducing seizures, providing a potential mechanism for the observed neuroprotective effects of a ketogenic diet [66, 202].

\section{Carbohydrates}

As a macronutrient class, carbohydrates (including dietary fiber) have a profound effect on the gut microbiota. In comparison to bacteria, humans have much fewer enzymes to break down carbohydrates [203] and what can be digested by these enzymes is absorbed in the small intestine. Dietary fiber passes undigested from the small intestine into the colonic environment [171] and the gut microbiota relies on these fibers for energy, which they target for disassembly with a combined 'toolkit' of thousands of enzymes [204]. Therefore, carbohydrates in the form of dietary fiber represent enormous potential for modulation of gut microbiota based upon the chemistry and accessibility of specific dietary fibers to microbial groups.

Increased intake of dietary fiber does not have an overall Bifidobacterium increasing effect, however, specific dietary fibers have been shown to selectively increase Bifidobacteria abundance [205]. Furthermore, increased intake of dietary fiber has been associated with an increase in gut microbial richness and/or diversity, especially in individuals with reduced diversity [206]. Long-term patterns of dietary fiber consumption can also shape the overall bacterial community type. As previously discussed, enterotype assignment to the Prevotella group has been suggested to be associated with high-fiber diets. O'Keefe et al. [207] studied the effects on gut microbiota when fat and fiber content of native African and African American diets were swapped for 2 weeks, such that African Americans consumed highfiber, low-fat rural African diets and vice versa. While changes in abundances of Bacteroides or Prevotella genera were not observed in either group, the high-fiber, low-fat diets enriched bacterial genes for butyrate production and decreased genes for secondary bile acid synthesis, emphasizing the importance of identifying functional rather than compositional shifts.

Endurance athletes are well known to follow diets that result in the consumption of high amounts of both simple and complex carbohydrates [208, 209]. This dietary pattern, in combination with the substantial number of hours spent exercising on a weekly basis, led to the hypothesis that endurance athletes are likely to have increased abundance of the bacterial genus Prevotella [208]. Prevotella is normally found in only a small percentage of healthy individuals in European and American cohorts [1, 2, 20, 210]. Previous microbiome studies have repeatedly identified significant correlations of both diet and geographic location to abundances of Prevotella or Bacteroides. Prevotella is more often found in individuals from certain areas of Asia [211, 212] and rural Africa [213], and this enrichment for Prevotella is often reflective of diets high in complex carbohydrates (including high dietary fiber from various sources including fruits and vegetables), egg food items, and high levels of vitamins and minerals [172, 211]. However, Prevotella has been noted to be associated with several disease states. For instance, Prevotella has been shown to be higher in patients with depression [214], insulin resistance [215], non-alcoholic fatty liver disease [216, 217], hypertension [217], and colon cancer [218]. One potential explanation for this phenomenon is that there are several strains within the Prevotella genus that exert pathogenic actions, which could help explain the bidirectional and almost opposing effects that Prevotella has shown to have in human health [219]. More studies in humans are needed to better understand Prevotella's role in athletes, as well as its role in disease. For this, more indepth metagenomic studies will be required to reveal the health- or disease-modulating properties of Prevotella, particularly at species and functional level [219].

Nutritional strategies (i.e., avoiding fat and fiber) have been recommended to reduce the risk of GI distress before and during training and competition [220]. These recommendations aim to support rapid gastric 
emptying, water and nutrient absorption and adequate perfusion of the splanchnic vasculature [221]. However, the lack of complex carbohydrates in elite athletes' diets may negatively affect the gut microbiota composition and function over time. Many athletes may not be consuming enough fiber that feed commensal bacteria that produce beneficial byproducts for host metabolism and homeostasis [15]. Furthermore, adding fiber, including resistant starch, to high protein diets may help reduce potential negative effects of high protein consumption [222] and may increase fat oxidation [202], further illustrating the importance of consuming adequate dietary fiber for gut and overall health.

Petersen et al. [18] reported increased abundance of M. smithii transcripts in professional cyclists using RNA sequencing. $M$. smithii increases the fermentation efficiency of many bacterial taxa in the gut, including those that ferment complex polysaccharides [223]. This effect could benefit athletes because an increase in bacterial fermentation products (such as SCFAs) could be absorbed and utilized by the host. Theoretically, this effect could enhance recovery from intense exercise and possibly race performance. SCFAs can improve skeletal muscle insulin sensitivity [224], reduce inflammation [225], and regulate satiety [226], all of which may contribute to the improvements in body composition observed in this study. Additionally, SCFAs are also energy substrates for numerous tissue types, including the colon [227], adipose [228] and muscle tissues [224], indicating that SCFAs can contribute to enhanced energy harvest from the diet, ultimately providing support to healthy tissue growth and turnover.

Within the SCFAs, distinct clusters (acetic acid, propionic acid, and butyric acid) were observed by Barton et al. [13] to positively correlate with dietary contributors (fiber and protein), while isobutyric acid, isovaleric acid, and valeric acid positively correlated with microbial diversity. The same clusters were observed when positively correlating with individual taxa, in support of purported links between SCFAs and numerous metabolic benefits and a lean phenotype [61-63].

\section{Fat}

Like protein and carbohydrate, the specific effects of fat on the gut microbiota are difficult to isolate; however, the types of fats consumed appear to be important. In a rodent study, animals fed lard showed increases in Bacteroides and displayed signs of metabolic dysfunction. In contrast, animals fed fish oil showed increased levels of lactic acid bacteria and were protected from metabolic dysfunction [229]. In humans, ingestion of an animal-based diet for 5 days, high in fat (69\% of total energy) and protein (30\% of total energy) and almost entirely void of carbohydrates (including dietary fiber), induced rapid and significant changes in microbial community structure and overwhelmed interindividual differences in microbial gene expression. Specific alterations included gut bacterial taxonomic shifts and transcriptional responses characteristic of carnivorous mammals, with higher concentrations of biletolerant bacteria (presumably due to the extremely highfat intake known to increase bile acid secretion) [134]. Diets high in fat could interact in various ways with the gut microbiota to facilitate the translocation of bacterial LPS generating chronic inflammation [171]. LPS can be incorporated into lipid micelles formed during fat digestion, and certain gut microbes may be important in regulating this process.

In a short-term feeding study Wu et al. [172] randomized ten subjects into a 10-day high-fat/low-fiber diet (38\% fat, 35\% carbohydrate, $27 \%$ protein) while others were given a high-fiber/low-fat diet (13\% fat, $69 \%$ carbohydrate, $18 \%$ protein). Although specific taxa changes varied between individuals, the high-fat diet slowed intestinal transit time by as much as 3 days. Metagenomic analysis indicated that functional shifts, including greater protein export and lipoic acid metabolism, were also associated with the high-fat diet. Finally, the Bacteroides enterotype was most strongly correlated with reports of frequent consumption of animal protein and saturated fat. Similarly, Murtaza and colleagues [230] completed a three-week diet intervention in elite race walkers undertaking intensified training combined with a ketogenic, low-carbohydrate, high-fat diet (LCHF; < $50 \mathrm{~g}$ day carbohydrate; $78 \%$ energy as fat; $2.1 \mathrm{~g} / \mathrm{kg} /$ day protein) and reported increased relative abundance of Bacteroides and Dorea and reduced Faecalibacterium. In comparison to high or periodized carbohydrate diet groups, the LCHF diet resulted in a more pronounced effect on the gut microbiota increasing the relative abundance of bacterial taxa with recognized capabilities for lipid metabolism. The relative abundance of Bacteroides spp. was negatively correlated with fat oxidation and the relative abundance of Dorea was negatively correlated with an exercise economy test. It appears that individual responsiveness to a high-fat diet may affect the amount of dietary fat that actually reaches the distal gut, where it could have associative effects on the gut microbiota. Furthermore, relative abundance of Faecalibacterium spp. was decreased in athletes after consumption of the LCHF diet. Interestingly, Faecalibacterium spp. is one of the most abundant bacterial taxa present in the gut microbiota of healthy individuals and has been linked to a host of metabolic products with anti-inflammatory effects [231]. Diets high in fat likely increase the pool of bile acids that elude epithelial absorption in the GI tract and interact with the gut microbiota [232]. This interaction can impact the composition of the gut microbiota 
including reductions in the relative abundance of Faecalibacterium spp. [233]. Faecalibacterium is widely recognized for its production of a suite of metabolites and peptides with anti-inflammatory effects [231].

\section{Summary of the effect of athletic diet on the gut microbiota} Overall, there is a need for longer-term studies in different athletic cohorts examining the impact of diet on the structure and function of the gut microbiota. This approach is of particular importance as many athletes follow special dietary practices, such as during periods of intensified training prior to competition and offseason periods. Research studies should investigate exercisenutrient interactions that underpin adaptation and performance [234]. Finally, further research is needed to determine the synthesis kinetics and clinical consequence of microbial by-products during increased nutritional status and metabolic demands during exercise. Ultimately modulation of the microbiota and its fermentation capacity may be considered in dietary prescription for athletes. This may include specific nutrient recommendations aimed at improving performance by enhancing certain metabolites during exercise and recovery, and limiting those that produce toxic metabolites that may made worsen the consequences of exercise stress [15].

\section{Key Points 3 - Influence of Athletic Diet on Gut Microbiota.}

- Diet is an established modulator of gut microbiota composition and activity, with marked changes in microbiota composition evident within $24 \mathrm{~h}$ of a dietary change.

- Energy balance is currently an overlooked factor in relation to the athletic gut microbiota, particularly in those affected by RED-S.

- To solely investigate the impact of total energy consumption without considering dietary variability is difficult (if not impossible).

- The effects of high-protein consumption (without concurrent high-fat) on gut bacteria are not well studied. This also includes the effects of high-protein and high-fiber intake.

- Protein intake appears to be a strong modulator of microbiota diversity, with protein supplementation, such as whey, showing potential benefits that need further study in humans.

- Proteins from vegetable origin have a marked effect on gut microbiota but currently require investigation in athletes.

- In future studies, the types and amounts of fats consumed in conjunction with protein should be investigated in the overall effect on the gut microbiota.

- Increased intake of dietary fiber is associated with microbial richness and/or diversity.

- Higher intake of carbohydrate and dietary fiber in athletes appear to be associated with increased abundance of Prevotella.

- The specific effects of fat on the gut microbiota is difficult to isolate; however, the types of fats consumed appear to be important.

\section{Conclusion}

The current body of literature, although limited, indicates that the cluster of athletic components such as exercise, associated dietary factors, and body composition promotes a more "health-associated" gut microbiota. Typical features include a higher abundance of health-promoting bacterial species, increased microbial diversity, functional pathways, and microbialassociated metabolites, stimulation of bacterial abundance that can modulate mucosal immunity, and improved barrier functions. In comparison to sedentary controls, athletes have increased fecal metabolites and improved overall health (unless over-trained or in REDS). However, in sedentary individuals, exercise appears to positively modulate the composition and metabolic capacity of the human gut microbiota. Given that athletes generally have a distinct diet, research on the gut microbiome in athletes must incorporate dietary and supplemental intake otherwise it might be a confounding factor in determining exercise-specific effects on the composition of the microbiome. While individuals' microbiotas appear to be driven by their primary dietary patterns, future research is needed to better describe the impact of high-protein consumption and (in conjunction) the types and amount of fiber and fats consumed. Investigators should examine how different types of sport, athlete, and physical training regimens influence the gut microbiota. The present review focuses on the discussion of the results from microbiota-related studies, however, a deep discussion of the methodological approaches of each manuscript was not possible due to the already extended content. Future, more specific reviews in this research area should aim for discussing the results in the frame of their methodological approaches. Finally, much of the current research is cross-sectional and has relied on $16 \mathrm{~S}$ rRNA sequencing. Therefore, future research should employ longitudinal designs as well as more advanced high-throughput sequencing and bioinformatic analyses to provide deeper understanding and functional causation of the gut microbial influence on athlete health and performance. This information can then be used to develop novel therapeutic and nutritional strategies to modulate the microbiota and enhance the athlete's overall performance and health. Ultimately this body of work will define how metabolic capabilities of gut microbiota are shaped by exercise and elucidate their functional roles influencing health and disease.

\footnotetext{
Abbreviations

BCAA: Branched-chain amino acid; BMI: Body mass index; Gl: Gastrointestinal; Kcal: Kilocalories; LCHF: Low-carbohydrate, high-fat; LPS: Lipopolysaccharide; OTUs: Operational taxonomic units; RED-S: Relative Energy Deficiency in Sports; rRNA: Ribosomal RNA; SFCA: Short chain fatty acid; Spp.: Species; $\mathrm{VO}_{2}$ : Volume of oxygen utilization
}

Acknowledgments

The authors would like to thank the participants and researchers who contributed works cited in this paper. 


\section{Authors' contributions}

AEM and RJ conceptualized and designed this review. AEM, RJ, KCC, and CMK prepared and compiled the first draft for review and editing. All other co-authors critically evaluated and revised the first draft and articles for inclusion. AEM completed the final draft of the manuscript which was reviewed, edited, and approved by all co-authors. The author(s) read and approved the final manuscript.

\section{Funding}

The publication fee was sponsored by Increnovo LLC. The authors received no remuneration for writing and/or reviewing this review.

\section{Availability of data and materials}

Not applicable.

\section{Ethics approval}

Not applicable.

\section{Consent for publication}

Not applicable.

\section{Competing interests}

$K B, L B$, and SDW declare no competing interests. RJ has received grants to evaluate the efficacy and safety of probiotics, serves on scientific advisory boards, and has served as an expert witness, legal and scientific consultant. AEM and KCC are employed by Isagenix, a company selling branded probiotics products. CMK has previously received external funding to conduct research studies involving nutritional supplements and is currently conducting studies involving prebiotics and probiotics. MP has received grants to evaluate the efficacy and safety of probiotics and has served as a scientific consultant. JRT reports no conflicts of interest regarding the material or paper presented. JRT has previously received grants to evaluate the efficacy of various nutritional supplements including probiotics. NPW reports no conflicts of interested regarding the paper presented and has been the recipient of external funding to conduct research on nutritional supplements on the microbiome in athletes. MG reports no conflicts of interest regarding the material or paper presented. MG has previously received external funding to conduct research studies involving nutritional supplements including probiotics. DBP reports no conflicts of interest regarding the material or paper presented, and has received grants to evaluate the effectiveness of probiotic supplementation in athletes. BIC has conducted industry sponsored studies at his university and occasionally serves as a scientific and legal consultant related to exercise and nutrition intervention studies. He also serves on the scientific advisory board of Dymatize (Post Holdings). RBK reports no conflicts of interest related to the material presented in this paper. He has conducted industry sponsored studies at the universities he has been affiliated with and occasionally serves as a scientific and legal consultant related to exercise and nutrition intervention studies. CJW is employed by Jamieson Labs, a company selling branded probiotics products. MPA is employed by Biolab research Srl, performing research \& development activities for Probiotical SpA, a leading probiotic supplier. DSK reports he works for a contract research organization that has received funding from the probiotic industry for clinical trials and serves on the Scientific Advisory Board for Dymatize (Post Holdings). JS is a co-founder of Fitbiomics, a company identifying, researching and commercializing new probiotic strains. JAT is employed by the International Probiotic Association and further consults within the probiotic and microbiome industries. PJA reports no conflicts of interest related to the material presented in this paper. He serves on the Scientific Advisory Board for Dymatize (Post Holdings), and Isagenix International LLC and has conducted industry sponsored studies involving nutritional supplements. SMA reports no conflicts of interest related to the material presented in this paper. He serves on the Scientific Advisory Board for Dymatize (Post Holdings) and has conducted industry sponsored studies involving nutritional supplements. JA is the CEO of the International Society of Sports Nutrition and reports no conflicts of interest with the material presented.

\section{Author details}

${ }^{1}$ College of Health Solutions, Arizona State University, Phoenix, AZ, USA. ${ }^{2}$ Increnovo LLC, Milwaukee, WI 53202, USA. ${ }^{3}$ Isagenix International LLC, Gilbert, AZ, USA. ${ }^{4}$ Exercise and Performance Nutrition Laboratory, School of
Health Sciences, Lindenwood University, St. Charles, MO, USA. ${ }^{5}$ Exercise and Nutrition Science Graduate Program, Lipscomb University, Nashville, TN 37204, USA. ${ }^{6}$ School of Medical Research and Menzies Health Institute of QLD, Griffith Health, Griffith University, Southport, Australia. ${ }^{7}$ Department of Human Nutrition, University of Otago, Dunedin, New Zealand. ${ }^{8}$ School of Sport, Exercise and Health Sciences, Loughborough University, Loughborough, UK. ${ }^{9}$ Research Institute for Sport and Exercise, University of Canberra, Canberra ACT 2617, Australia. ${ }^{10}$ WGI, Lewisville, TX, USA.

${ }^{11}$ Department of Exercise Science, Arnold School of Public Health, University of South Carolina, Columbia, SC, USA. ${ }^{12}$ Exercise \& Sport Nutrition Lab, Human Clinical Research Facility, Department of Health \& Kinesiology, Texas A\&M University, College Station, TX 77843-4253, USA. ${ }^{13}$ Performance \& Physique Enhancement Laboratory, University of South Florida, Tampa, FL, USA. ${ }^{14}$ Institute of Performance Nutrition, London, UK. ${ }^{15}$ Fitbiomics, Inc, New York, NY, USA. ${ }^{16}$ Jamieson Wellness Inc., 4025 Rhodes Drive, Windsor, Ontario N8W 5B5, Canada. ${ }^{17}$ Bioloab Research, Via E. Mattei 3, 28100 Novara, Italy. ${ }^{18}$ Scientific Affairs, Nutrasource Diagnostics, Inc. Guelph, Guelph, Ontario, Canada. ${ }^{19}$ Research Institute for Sport and Exercise Sciences, Liverpool John Moores University, Tom Reilly Building, Byrom St Campus, Liverpool L3 3AF, UK. ${ }^{20}$ International Probiotic Association, Los Angeles, CA, USA. ${ }^{21} \mathrm{Health}$ and Human Physiological Sciences Department, Skidmore College, Saratoga Springs, NY, USA. ${ }^{22}$ Exercise and Sport Science, Nova Southeastern University, Davie, FL, USA.

Received: 9 January 2020 Accepted: 28 April 2020

Published online: 12 May 2020

\section{References}

1. Human Microbiome Project C. Structure, function and diversity of the healthy human microbiome. Nature. 2012;486(7402):207-14 https://doi.org/ 10.1038/nature11234.

2. Qin J, Li R, Raes J, Arumugam M, Burgdorf KS, Manichanh C, et al. A human gut microbial gene catalogue established by metagenomic sequencing. Nature. 2010;464(7285):59-65 https://doi.org/10.1038/nature08821.

3. Cronin O, Molloy MG, Shanahan F. Exercise, fitness, and the gut. Curr Opin Gastroenterol. 2016;32(2):67-73 https://doi.org/10.1097/MOG. 0000000000000240

4. Ursell LK, Metcalf JL, Parfrey LW, Knight R. Defining the human microbiome. Nutr Rev. 2012;70(Suppl 1):S38-44 https://doi.org/10.1111/j.1753-4887.2012. 00493.x

5. Duffy LC, Raiten DJ, Hubbard VS, Starke-Reed P. Progress and challenges in developing metabolic footprints from diet in human gut microbial cometabolism. J Nutr. 2015;145(5):1123S-30S https://doi.org/10.3945/jn.114. 194936.

6. Costello EK, Lauber CL, Hamady M, Fierer N, Gordon JI, Knight R. Bacterial community variation in human body habitats across space and time. Science. 2009;326(5960):1694-7 https://doi.org/10.1126/science.1177486.

7. Yatsunenko T, Rey FE, Manary MJ, Trehan I, Dominguez-Bello MG, Contreras $\mathrm{M}$, et al. Human gut microbiome viewed across age and geography. Nature. 2012;486(7402):222-7 https://doi.org/10.1038/nature11053.

8. Dudek-Wicher RK, Junka A, Bartoszewicz M. The influence of antibiotics and dietary components on gut microbiota. Prz Gastroenterol. 2018;13(2):85-92 https://doi.org/10.5114/pg.2018.76005.

9. Flint HJ, Duncan SH, Scott KP, Louis P. Links between diet, gut microbiota composition and gut metabolism. Proc Nutr Soc. 2015;74(1):13-22 https:// doi.org/10.1017/S0029665114001463.

10. Wampach L, Heintz-Buschart A, Fritz JV, Ramiro-Garcia J, Habier J, Herold M, et al. Birth mode is associated with earliest strain-conferred gut microbiome functions and immunostimulatory potential. Nat Commun. 2018;9(1):5091 https://doi.org/10.1038/s41467-018-07631-x.

11. Jang LG, Choi G, Kim SW, Kim BY, Lee S, Park H. The combination of sport and sport-specific diet is associated with characteristics of gut microbiota: an observational study. J Int Soc Sports Nutr. 2019;16(1):21 https://doi.org/ 10.1186/s12970-019-0290-y.

12. Bermon S, Petriz B, Kajeniene A, Prestes J, Castell L, Franco OL. The microbiota: an exercise immunology perspective. Exerc Immunol Rev. 2015; 21:70-9.

13. Barton W, Penney NC, Cronin O, Garcia-Perez I, Molloy MG, Holmes E, et al. The microbiome of professional athletes differs from that of more sedentary subjects in composition and particularly at the functional metabolic level. Gut. 2018;67(4):625-33. https://doi.org/10.1136/gutjnl-2016-313627. 
14. Estaki M, Pither J, Baumeister P, Little JP, Gill SK, Ghosh S, et al. Cardiorespiratory fitness as a predictor of intestinal microbial diversity and distinct metagenomic functions. Microbiome. 2016;4(1):42 https://doi.org/10. 1186/s40168-016-0189-7.

15. Clark A, Mach N. Exercise-induced stress behavior, gut-microbiota-brain axis and diet: a systematic review for athletes. J Int Soc Sports Nutr. 2016;13:43 https://doi.org/10.1186/s12970-016-0155-6.

16. Scheiman J, Luber JM, Chavkin TA, MacDonald T, Tung A, Pham LD, et al. Meta-omics analysis of elite athletes identifies a performance-enhancing microbe that functions via lactate metabolism. Nat Med. 2019;25(7):1104-9 https://doi.org/10.1038/s41591-019-0485-4

17. Cerda B, Perez M, Perez-Santiago JD, Tornero-Aguilera JF, Gonzalez-Soltero R, Larrosa M. Gut microbiota modification: another piece in the puzzle of the benefits of physical exercise in health? Front Physiol. 2016;7:51 https:// doi.org/10.3389/fphys.2016.00051

18. Petersen LM, Bautista EJ, Nguyen H, Hanson BM, Chen L, Lek SH, et al. Community characteristics of the gut microbiomes of competitive cyclists. Microbiome. 2017;5(1):98 https://doi.org/10.1186/s40168-017-0320-4.

19. Clarke SF, Murphy EF, O'Sullivan O, Lucey AJ, Humphreys M, Hogan A, et al. Exercise and associated dietary extremes impact on gut microbial diversity. Gut. 2014;63(12):1913-20. https://doi.org/10.1136/gutjnl-2013-306541.

20. Zhou Y, Mihindukulasuriya KA, Gao H, La Rosa PS, Wylie KM, Martin JC, et al. Exploration of bacterial community classes in major human habitats. Genome Biol. 2014;15(5):R66 https://doi.org/10.1186/gb-2014-15-5-r66.

21. O'Sullivan A, Farver M, Smilowitz JT. The influence of early infant-feeding practices on the intestinal microbiome and body composition in infants. Nutr Metab Insights. 2015;8(Suppl 1):1-9 https://doi.org/10.4137/NMI.S29530.

22. Stein MM, Hrusch CL, Gozdz J, Igartua C, Pivniouk V, Murray SE, et al. Innate immunity and asthma risk in Amish and Hutterite farm children. N Engl J Med. 2016;375(5):411-21 https://doi.org/10.1056/NEJMoa1508749.

23. Zhang L, Nichols RG, Correll J, Murray IA, Tanaka N, Smith PB, et al. Persistent organic pollutants modify gut microbiota-host metabolic homeostasis in mice through aryl hydrocarbon receptor activation. Environ Health Perspect. 2015;123(7):679-88 https://doi.org/10.1289/ehp.1409055.

24. Fouhy F, Watkins C, Hill CJ, O'Shea CA, Nagle B, Dempsey EM, et al. Perinatal factors affect the gut microbiota up to four years after birth. Nat Commun 2019;10(1):1517 https://doi.org/10.1038/s41467-019-09252-4.

25. Hollister EB, Riehle K, Luna RA, Weidler EM, Rubio-Gonzales M, Mistretta TA, et al. Structure and function of the healthy pre-adolescent pediatric gut microbiome. Microbiome. 2015;3:36 https://doi.org/10.1186/s40168-015-0101-x.

26. Eckburg PB, Bik EM, Bernstein CN, Purdom E, Dethlefsen L, Sargent M, et al. Diversity of the human intestinal microbial flora. Science. 2005;308(5728): 1635-8 https://doi.org/10.1126/science.1110591.

27. Wu HJ, Wu E. The role of gut microbiota in immune homeostasis and autoimmunity. Gut Microbes. 2012;3(1):4-14 https//doi.org/10.4161/gmic.19320.

28. Harsch IA, Konturek PC. The Role of Gut Microbiota in Obesity and Type 2 and Type 1 Diabetes Mellitus: New Insights into "Old" Diseases. Med Sci (Basel). 2018;6(2) https://doi.org/10.3390/medsci6020032.

29. Mayer EA, Tillisch K, Gupta A. Gut/brain axis and the microbiota. J Clin Invest. 2015;125(3):926-38 https://doi.org/10.1172/JCl76304.

30. Ishiguro $E_{1}$ Haskey N, Campbell K. Gut microbiota: interactive effects of nutrition and health: Elsevier; 2018.

31. Tierney BT, Yang Z, Luber JM, Beaudin M, Wibowo MC, Baek C, et al. The landscape of genetic content in the gut and Oral human microbiome. Cell Host Microbe. 2019;26(2):283-95. e8 https://doi.org/10.1016/j.chom.2019.07.008.

32. Roager HM, Hansen LB, Bahl MI, Frandsen HL, Carvalho V, Gobel RJ, et al. Colonic transit time is related to bacterial metabolism and mucosal turnover in the gut. Nat Microbiol. 2016;1(9):16093 https://doi.org/10.1038/ nmicrobiol.2016.93.

33. Laureto L, Cianciaruso M, Samia D. Functional diversity: an overview of its history and applicability. Natureza \& Conservacao. 2015;13(2):112-6 https:// doi.org/10.1016/j.ncon.2015.11.001.

34. Backhed F, Fraser CM, Ringel Y, Sanders ME, Sartor RB, Sherman PM, et al. Defining a healthy human gut microbiome: current concepts, future directions, and clinical applications. Cell Host Microbe. 2012;12(5):611-22 https://doi.org/10.1016/j.chom.2012.10.012.

35. Lloyd-Price J, Abu-Ali G, Huttenhower C. The healthy human microbiome. Genome Med. 2016;8(1):51 https://doi.org/10.1186/s13073-016-0307-y.

36. Lozupone CA, Stombaugh JI, Gordon JI, Jansson JK, Knight R. Diversity, stability and resilience of the human gut microbiota. Nature. 2012;489(7415): 220-30 https://doi.org/10.1038/nature11550.
37. Rodriguez JM, Murphy K, Stanton C, Ross RP, Kober OI, Juge N, et al. The composition of the gut microbiota throughout life, with an emphasis on early life. Microb Ecol Health Dis. 2015;26:26050 https://doi.org/10.3402/ mehd.v26.26050.

38. Faith JJ, Guruge JL, Charbonneau M, Subramanian S, Seedorf H, Goodman $\mathrm{AL}$, et al. The long-term stability of the human gut microbiota. Science. 2013;341(6141):1237439 https://doi.org/10.1126/science.1237439.

39. Visconti A, Le Roy Cl, Rosa F, Rossi N, Martin TC, Mohney RP, et al. Interplay between the human gut microbiome and host metabolism. Nat Commun. 2019;10(1):4505 https://doi.org/10.1038/s41467-019-12476-z.

40. Heintz-Buschart A, Wilmes P. Human gut microbiome: function matters. Trends Microbiol. 2018;26(7):563-74 https://doi.org/10.1016/j.tim.2017.11.002

41. Turnbaugh PJ, Gordon J. An invitation to the marriage of metagenomics and metabolomics. Cell. 2008;134(5):708-13 https://doi.org/10.1016/j.cell. 2008.08.025

42. Allaband C, McDonald D, Vazquez-Baeza Y, Minich JJ, Tripathi A, Brenner DA, et al. Microbiome 101: studying, analyzing, and interpreting gut microbiome data for clinicians. Clin Gastroenterol Hepatol. 2019;17(2):21830 https://doi.org/10.1016/j.cgh.2018.09.017

43. Knight R, Callewaert C, Marotz C, Hyde ER, Debelius JW, McDonald D, et al. The microbiome and human biology. Annu Rev Genomics Hum Genet. 2017;18:65-86 https://doi.org/10.1146/annurev-genom-083115-022438.

44. Goodrich JK, Di Rienzi SC, Poole AC, Koren O, Walters WA, Caporaso JG, et al. Conducting a microbiome study. Cell. 2014;158(2):250-62 https://doi. org/10.1016/j.cell.2014.06.037.

45. Poretsky R, Rodriguez RL, Luo C, Tsementzi D, Konstantinidis KT. Strengths and limitations of $16 \mathrm{~S}$ rRNA gene amplicon sequencing in revealing temporal microbial community dynamics. PLoS One. 2014;9(4):e93827 https://doi.org/10.1371/journal.pone.0093827.

46. Janda JM, Abbott SL. 16S rRNA gene sequencing for bacterial identification in the diagnostic laboratory: pluses, perils, and pitfalls. J Clin Microbiol. 2007; 45(9):2761-4 https://doi.org/10.1128/JCM.01228-07.

47. Lozupone CA, Hamady M, Kelley ST, Knight R. Quantitative and qualitative beta diversity measures lead to different insights into factors that structure microbial communities. Appl Environ Microbiol. 2007;73(5):1576-85 https:// doi.org/10.1128/AEM.01996-06.

48. Vernocchi P, Del Chierico F, Putignani L. Gut microbiota profiling: metabolomics based approach to unravel compounds affecting human health. Front Microbiol. 2016;7:1144 https://doi.org/10.3389/fmicb.2016. 01144.

49. Marcobal A, Kashyap PC, Nelson TA, Aronov PA, Donia MS, Spormann A, et al. A metabolomic view of how the human gut microbiota impacts the host metabolome using humanized and gnotobiotic mice. ISME J. 2013; 7(10):1933-43 https://doi.org/10.1038/ismej.2013.89.

50. Zierer J, Jackson MA, Kastenmuller G, Mangino M, Long T, Telenti A, et al. The fecal metabolome as a functional readout of the gut microbiome. Nat Genet. 2018:50(6):790-5 https://doi.org/10.1038/s41588-018-0135-7.

51. Bisanz JE, Upadhyay V, Turnbaugh JA, Ly K, Turnbaugh PJ. Meta-analysis reveals reproducible gut microbiome alterations in response to a high-fat diet. Cell Host Microbe. 2019;26(2):265-72.e4 https://doi.org/10.1016/j.chom. 2019.06.013.

52. Barb JJ, Oler AJ, Kim HS, Chalmers N, Wallen GR, Cashion A, et al. Development of an analysis pipeline characterizing multiple hypervariable regions of 16S rRNA using mock samples. PLoS One. 2016;11(2):e0148047 https://doi.org/10.1371/journal.pone.0148047.

53. Kemppainen KM, Ardissone AN, Davis-Richardson AG, Fagen JR, Gano KA, Leon-Novelo LG, et al. Early childhood gut microbiomes show strong geographic differences among subjects at high risk for type 1 diabetes. Diabetes Care. 2015;38(2):329-32 https://doi.org/10.2337/dc14-0850.

54. Lee S, Sung J, Lee J, Ko G. Comparison of the gut microbiotas of healthy adult twins living in South Korea and the United States. Appl Environ Microbiol. 2011;77(20):7433-7 https://doi.org/10.1128/AEM.05490-11.

55. Liu Z, DeSantis TZ, Andersen GL, Knight R. Accurate taxonomy assignments from $16 \mathrm{~S}$ rRNA sequences produced by highly parallel pyrosequencers. Nucleic Acids Res. 2008;36(18):e120 https://doi.org/10.1093/nar/gkn491.

56. Bressa C, Bailen-Andrino M, Perez-Santiago J, Gonzalez-Soltero R, Perez M, Montalvo-Lominchar MG, et al. Differences in gut microbiota profile between women with active lifestyle and sedentary women. PLoS One. 2017;12(2):e0171352 https://doi.org/10.1371/journal.pone.0171352.

57. Morkl S, Lackner S, Muller W, Gorkiewicz G, Kashofer K, Oberascher A, et al. Gut microbiota and body composition in anorexia nervosa inpatients in 
comparison to athletes, overweight, obese, and normal weight controls. Int J Eat Disord. 2017;50(12):1421-31 https://doi.org/10.1002/eat.22801.

58. O'Donovan CM, Madigan SM, Garcia-Perez I, Rankin A. O OS, Cotter PD. distinct microbiome composition and metabolome exists across subgroups of elite Irish athletes. J Sci Med Sport. 2020;23(1):63-8 https://doi.org/10. 1016/j.jsams.2019.08.290.

59. Dao MC, Everard A, Aron-Wisnewsky J, Sokolovska N, Prifti E, Verger EO, et al. Akkermansia muciniphila and improved metabolic health during a dietary intervention in obesity: relationship with gut microbiome richness and ecology. Gut. 2016;65(3):426-36. https://doi.org/10.1136/gutjnl-2014308778.

60. Flint HJ, Scott KP, Duncan SH, Louis P, Forano E. Microbial degradation of complex carbohydrates in the gut. Gut Microbes. 2012;3(4):289-306 https:// doi.org/10.4161/gmic.19897.

61. Hamer HM, Jonkers DM, Bast A, Vanhoutvin SA, Fischer MA, Kodde A, et al. Butyrate modulates oxidative stress in the colonic mucosa of healthy humans. Clin Nutr. 2009;28(1):88-93 https:/doi.org/10.1016/j.clnu.2008.11.002.

62. Koh A, De Vadder F, Kovatcheva-Datchary P, Backhed F. From dietary Fiber to host physiology: short-chain fatty acids as key bacterial metabolites. Cell. 2016;165(6):1332-45 https://doi.org/10.1016/j.cell.2016.05.041.

63. Ridaura VK, Faith JJ, Rey FE, Cheng J, Duncan AE, Kau AL, et al. Gut microbiota from twins discordant for obesity modulate metabolism in mice. Science. 2013;341(6150):1241214 https://doi.org/10.1126/science.1241214.

64. den Besten G, van Eunen K, Groen AK, Venema K, Reijngoud DJ, Bakker BM. The role of short-chain fatty acids in the interplay between diet, gut microbiota, and host energy metabolism. J Lipid Res. 2013;54(9):2325-40 https://doi.org/10.1194/jlr. R036012.

65. Everard A, Belzer C, Geurts L, Ouwerkerk JP, Druart C, Bindels LB, et al. Crosstalk between Akkermansia muciniphila and intestinal epithelium controls diet-induced obesity. Proc Natl Acad Sci U S A. 2013;110(22):9066-71 https://doi.org/10.1073/pnas.1219451110.

66. Olson CA, Vuong HE, Yano JM, Liang QY, Nusbaum DJ, Hsiao EY. The gut microbiota mediates the anti-seizure effects of the ketogenic diet. Cell. 2018;174(2):497 https://doi.org/10.1016/j.cell.2018.04.027.

67. Maffetone PB, Laursen PB. Athletes: fit but unhealthy? Sports Med Open. 2015;2:24 https://doi.org/10.1186/s40798-016-0048-x.

68. Cox AJ, West NP, Cripps AW. Obesity, inflammation, and the gut microbiota. Lancet Diabetes Endocrinol. 2015;3(3):207-15 https://doi.org/10.1016/S22138587(14)70134-2

69. Khan MJ, Gerasimidis K, Edwards CA, Shaikh MG. Role of gut microbiota in the Aetiology of obesity: proposed mechanisms and review of the literature. J Obes. 2016;2016:7353642. https://doi.org/10.1155/2016/7353642.

70. Lira FS, Rosa JC, Pimentel GD, Souza HA, Caperuto EC, Carnevali LC Jr, et al. Endotoxin levels correlate positively with a sedentary lifestyle and negatively with highly trained subjects. Lipids Health Dis. 2010;9:82 https:// doi.org/10.1186/1476-511X-9-82.

71. Cook MD, Allen JM, Pence BD, Wallig MA, Gaskins HR, White BA, et al. Exercise and gut immune function: evidence of alterations in colon immune cell homeostasis and microbiome characteristics with exercise training. Immunol Cell Biol. 2016;94(2):158-63 https://doi.org/10.1038/icb. 2015.108.

72. Matsumoto M, Inoue R, Tsukahara T, Ushida K, Chiji H, Matsubara N, et al. Voluntary running exercise alters microbiota composition and increases nbutyrate concentration in the rat cecum. Biosci Biotechnol Biochem. 2008; 72(2):572-6 https://doi.org/10.1271/bbb.70474

73. Choi JJ, Eum SY, Rampersaud E, Daunert S, Abreu MT, Toborek M. Exercise attenuates PCB-induced changes in the mouse gut microbiome. Environ Health Perspect. 2013;121(6):725-30 https://doi.org/10.1289/ehp.1306534.

74. Evans CC, LePard KJ, Kwak JW, Stancukas MC, Laskowski S, Dougherty J, et al. Exercise prevents weight gain and alters the gut microbiota in a mouse model of high fat diet-induced obesity. PLoS One. 2014;9(3):e92193 https://doi.org/10.1371/journal.pone.0092193.

75. Lambert JE, Myslicki JP, Bomhof MR, Belke DD, Shearer J, Reimer RA. Exercise training modifies gut microbiota in normal and diabetic mice. Appl Physiol Nutr Metab. 2015;40(7):749-52 https://doi.org/10.1139/apnm-2014-0452.

76. Mathur R, Barlow GM. Obesity and the microbiome. Expert Rev Gastroenterol Hepatol. 2015;9(8):1087-99 https://doi.org/10.1586/17474124. 2015.1051029.

77. Salonen A, de Vos WM, Palva A. Gastrointestinal microbiota in irritable bowel syndrome: present state and perspectives. Microbiology. 2010;156(Pt 11):3205-15 https://doi.org/10.1099/mic.0.043257-0.
78. Larsen N, Vogensen FK, van den Berg FW, Nielsen DS, Andreasen AS, Pedersen BK, et al. Gut microbiota in human adults with type 2 diabetes differs from non-diabetic adults. PLoS One. 2010;5(2):e9085 https://doi.org/ 10.1371/journal.pone.0009085.

79. Ley RE, Turnbaugh PJ, Klein S, Gordon JI. Microbial ecology: human gut microbes associated with obesity. Nature. 2006;444(7122):1022-3 https://doi. org/10.1038/4441022a

80. Ley RE, Backhed F, Turnbaugh P, Lozupone CA, Knight RD, Gordon Jl. Obesity alters gut microbial ecology. Proc Natl Acad Sci U S A. 2005;102(31): 11070-5 https://doi.org/10.1073/pnas.0504978102.

81. Kasai C, Sugimoto K, Moritani I, Tanaka J, Oya Y, Inoue H, et al. Comparison of the gut microbiota composition between obese and non-obese individuals in a Japanese population, as analyzed by terminal restriction fragment length polymorphism and next-generation sequencing. BMC Gastroenterol. 2015;15:100 https://doi.org/10.1186/s12876-015-0330-2.

82. Koliada A, Syzenko G, Moseiko V, Budovska L, Puchkov K, Perederiy V, et al. Association between body mass index and Firmicutes/Bacteroidetes ratio in an adult Ukrainian population. BMC Microbiol. 2017;17(1):120 https://doi. org/10.1186/s12866-017-1027-1.

83. Walters WA, Xu Z, Knight R. Meta-analyses of human gut microbes associated with obesity and IBD. FEBS Lett. 2014;588(22):4223-33 https://doi. org/10.1016/j.febslet.2014.09.039.

84. Finucane MM, Sharpton TJ, Laurent TJ, Pollard KS. A taxonomic signature of obesity in the microbiome? Getting to the guts of the matter. PLoS One. 2014;9(1):e84689 https://doi.org/10.1371/journal.pone.0084689.

85. Johnson EL, Heaver SL, Walters WA, Ley RE. Microbiome and metabolic disease: revisiting the bacterial phylum Bacteroidetes. J Mol Med (Berl). 2017;95(1):1-8 https://doi.org/10.1007/s00109-016-1492-2.

86. Petriz BA, Castro AP, Almeida JA, Gomes CP, Fernandes GR, Kruger RH, et al. Exercise induction of gut microbiota modifications in obese, non-obese and hypertensive rats. BMC Genomics. 2014;15:511 https://doi.org/10.1186/14712164-15-511.

87. Queipo-Ortuno MI, Seoane LM, Murri M, Pardo M, Gomez-Zumaquero JM, Cardona F, et al. Gut microbiota composition in male rat models under different nutritional status and physical activity and its association with serum leptin and ghrelin levels. PLoS One. 2013;8(5):e65465 https://doi.org/ 10.1371/journal.pone.0065465.

88. Campbell SC, Wisniewski PJ, Noji M, McGuinness LR, Haggblom MM, Lightfoot SA, et al. The effect of diet and exercise on intestinal integrity and microbial diversity in mice. PLoS One. 2016;11(3):e0150502 https://doi.org/ 10.1371/journal.pone.0150502.

89. Kang SS, Jeraldo PR, Kurti A, Miller ME, Cook MD, Whitlock K, et al. Diet and exercise orthogonally alter the gut microbiome and reveal independent associations with anxiety and cognition. Mol Neurodegener. 2014;9:36 https://doi.org/10.1186/1750-1326-9-36.

90. Mika A, Van Treuren W, Gonzalez A, Herrera JJ, Knight R, Fleshner M. Exercise is more effective at altering gut microbial composition and producing stable changes in lean mass in juvenile versus adult male F344 rats. PLoS One. 2015;10(5):e0125889 https://doi.org/10.1371/journal.pone. 0125889.

91. Bocker U, Nebe T, Herweck F, Holt L, Panja A, Jobin C, et al. Butyrate modulates intestinal epithelial cell-mediated neutrophil migration. Clin Exp Immunol. 2003;131(1):53-60 https://doi.org/10.1046/.1365-2249.2003.02056.x.

92. Monteiro R, Azevedo I. Chronic inflammation in obesity and the metabolic syndrome. Mediat Inflamm. 2010;2010. https://doi.org/10.1155/2010/289645.

93. Durk RP, Castillo E, Marquez-Magana L, Grosicki GJ, Bolter ND, Lee CM, et al. Gut microbiota composition is related to cardiorespiratory fitness in healthy Young adults. Int J Sport Nutr Exerc Metab. 2019;29(3):249-53 https://doi. org/10.1123/ijsnem.2018-0024.

94. Yang $Y$, Shi $Y$, Wiklund $P$, Tan $X$, Wu N, Zhang $X$, et al. The association between cardiorespiratory fitness and gut microbiota composition in premenopausal women. Nutrients. 2017;9(8):792 https://doi.org/10.3390/ nu9080792.

95. Clavel $T$, Lepage $P$, Charrier C. The family Coriobacteriaceae. In: Rosenberg $E_{,}$ DeLong EF, Lory S, Stackebrandt E, Thompson F, editors. The prokaryotes. Berlin: Springer; 2014.

96. Rycroft AN, Garside LH. Actinobacillus species and their role in animal disease. Vet J. 2000;159(1):18-36 https://doi.org/10.1053/tvjl.1999.0403.

97. Ng SK, Hamilton IR. Carbon dioxide fixation by Veillonella parvula M 4 and its relation to propionic acid formation. Can J Microbiol. 1973;19(6):715-23 https://doi.org/10.1139/m73-116. 
98. Allen JM, Mailing LJ, Niemiro GM, Moore R, Cook MD, White BA, et al. Exercise alters gut microbiota composition and function in lean and obese humans. Med Sci Sports Exerc. 2018;50(4):747-57 https://doi.org/10.1249/ MSS.0000000000001495.

99. Keohane DM, Woods T, O'Connor P, Underwood S, Cronin O, Whiston R, et al. Four men in a boat: ultra-endurance exercise alters the gut microbiome. J Sci Med Sport. 2019;22(9):1059-64 https://doi.org/10.1016/j. jsams.2019.04.004

100. Hawley JA. Microbiota and muscle highway - two way traffic. Nat Rev Endocrinol. 2019;16(2):71-2 https://doi.org/10.1038/s41574-019-0291-6.

101. Taniguchi H, Tanisawa K, Sun X, Kubo T, Hoshino Y, Hosokawa M, et al. Effects of short-term endurance exercise on gut microbiota in elderly men. Phys Rep. 2018;6(23):e13935. https://doi.org/10.14814/phy2.13935.

102. Pluznick JL. Microbial short-chain fatty acids and blood pressure regulation. Curr Hypertens Rep. 2017;19(4):25 https://doi.org/10.1007/s11906-017-0722-5.

103. Morita E, Yokoyama H, Imai D, Takeda R, Ota A, Kawai E, et al. Aerobic exercise training with brisk walking increases intestinal Bacteroides in healthy elderly women. Nutrients. 2019;11(4):868 https://doi.org/10.3390/ nu11040868.

104. Santacruz A, Collado MC, Garcia-Valdes L, Segura MT, Martin-Lagos JA, Anjos $T$, et al. Gut microbiota composition is associated with body weight, weight gain and biochemical parameters in pregnant women. Br J Nutr. 2010; 104(1):83-92 https://doi.org/10.1017/S0007114510000176.

105. Abenavoli L, Scarpellini E, Colica C, Boccuto L, Salehi B, Sharifi-Rad J, et al. Gut microbiota and obesity: a role for probiotics. Nutrients. 2019;11(11):2690 https://doi.org/10.3390/nu11112690.

106. Liu Y, Wang Y, Ni Y, Cheung CKY, Lam KSL, Wang Y, et al. Gut Microbiome Fermentation Determines the Efficacy of Exercise for Diabetes Prevention. Cell Metab. 2019;31(1):P77-91.E5 https://doi.org/10.1016/j.cmet.2019.11.001.

107. Newgard CB, An J, Bain JR, Muehlbauer MJ, Stevens RD, Lien LF, et al. A branched-chain amino acid-related metabolic signature that differentiates obese and lean humans and contributes to insulin resistance. Cell Metab. 2009;9(4):311-26 https://doi.org/10.1016/j.cmet.2009.02.002.

108. Kern T, Blond MB, Hansen TH, Rosenkilde M, Quist JS, Gram AS, et al. Structured exercise alters the gut microbiota in humans with overweight and obesity-a randomized controlled trial. Int J Obes. 2019;44:125-35 https://doi.org/10.1038/s41366-019-0440-y.

109. Motiani KK, Collado MC, Eskelinen JJ, Virtanen KA, Loyttyniemi E, Salminen S, et al. Exercise training modulates gut microbiota profile and improves Endotoxemia. Med Sci Sports Exerc. 2019;52(1):94-104 https://doi.org/10. 1249/MSS.0000000000002112.

110. Rajilic-Stojanovic M, de Vos WM. The first 1000 cultured species of the human gastrointestinal microbiota. FEMS Microbiol Rev. 2014;38(5):996-1047 https://doi.org/10.1111/1574-6976.12075.

111. Tuovinen E, Keto J, Nikkila J, Matto J, Lahteenmaki K. Cytokine response of human mononuclear cells induced by intestinal Clostridium species. Anaerobe. 2013;19:70-6 https://doi.org/10.1016/j.anaerobe.2012.11.002.

112. Ohtani M, Sugita M, Maruyama K. Amino acid mixture improves training efficiency in athletes. J Nutr. 2006;136(2):538S-43S https://doi.org/10.1093/ $\mathrm{jn} / 136.2 .538 \mathrm{~S}$.

113. Metges CC. Contribution of microbial amino acids to amino acid homeostasis of the host. J Nutr. 2000;130(7):1857S-64S https://doi.org/10. 1093/jn/130.7.1857S.

114. Gisolfi CV. Is the Gl system built for exercise? News Physiol Sci. 2000;15:1149 https://doi.org/10.1152/physiologyonline.2000.15.3.114.

115. Rosa EF, Silva AC, Ihara SS, Mora OA, Aboulafia J, Nouailhetas VL. Habitual exercise program protects murine intestinal, skeletal, and cardiac muscles against aging. J Appl Physiol. 2005;99(4):1569-75 https://doi.org/10.1152/ japplphysiol.00417.2005.

116. Tottey W, Feria-Gervasio D, Gaci N, Laillet B, Pujos E, Martin JF, et al. Colonic transit time is a driven force of the gut microbiota composition and metabolism: in vitro evidence. J Neurogastroenterol Motil. 2017;23(1):124-34 https://doi.org/10.5056/jnm16042.

117. Abbas A, Wilding G, Sitrin M. Does colonic transit time affect colonic pH? J Gastroenterol Hepatol Res. 2014;3(6):1103-7. https://doi.org/10.6051/j.issn. 2224-3992.2014.03.399.

118. Strid H, Simren M, Storsrud S, Stotzer PO, Sadik R. Effect of heavy exercise on gastrointestinal transit in endurance athletes. Scand J Gastroenterol. 2011;46(6):673-7 https://doi.org/10.3109/00365521.2011.558110.

119. De Schryver AM, Keulemans YC, Peters HP, Akkermans LM, Smout AJ, De Vries WR, et al. Effects of regular physical activity on defecation pattern in middle-aged patients complaining of chronic constipation. Scand J Gastroenterol. 2005;40(4):422-9 https://doi.org/10.1080/00365520510011641.

120. Oettle GJ. Effect of moderate exercise on bowel habit. Gut. 1991;32(8):941-4 https://doi.org/10.1136/gut.32.8.941.

121. Horner KM, Schubert MM, Desbrow B, Byrne NM, King NA. Acute exercise and gastric emptying: a meta-analysis and implications for appetite control. Sports Med. 2015;45(5):659-78 https://doi.org/10.1007/s40279-014-0285-4.

122. Rehrer NJ, Beckers E, Brouns F, Hoor ten F, Saris WH. Exercise and training effects on gastric emptying of carbohydrate beverages. Med Sci Sports Exerc. 1989;21(5):540-9 https://doi.org/10.1249/00005768-198910000-00008.

123. Neufer PD, Young AJ, Sawka MN. Gastric emptying during walking and running: effects of varied exercise intensity. Eur J Appl Physiol Occup Physiol. 1989;58(4):440-5 https://doi.org/10.1007/bf00643522.

124. Feldman M, Nixon JV. Effect of exercise on postprandial gastric secretion and emptying in humans. J Appl Physiol Respir Environ Exerc Physiol. 1982; 53(4):851-4 https://doi.org/10.1152/jappl.1982.53.4.851.

125. Walker AW, Duncan SH, McWilliam Leitch EC, Child MW, Flint HJ. pH and peptide supply can radically alter bacterial populations and short-chain fatty acid ratios within microbial communities from the human colon. Appl Environ Microbiol. 2005;71(7):3692-700 https://doi.org/10.1128/AEM.71.7. 3692-3700.2005

126. Qamar MI, Read AE. Effects of exercise on mesenteric blood flow in man. Gut. 1987;28(5):583-7 https://doi.org/10.1136/gut.28.5.583.

127. de Oliveira EP, Burini RC. The impact of physical exercise on the gastrointestinal tract. Curr Opin Clin Nutr Metab Care. 2009;12(5):533-8 https://doi.org/10.1097/MCO.0b013e32832e6776.

128. Oktedalen O, Lunde OC, Opstad PK, Aabakken L, Kvernebo K. Changes in the gastrointestinal mucosa after long-distance running. Scand J Gastroenterol. 1992;27(4):270-4 https://doi.org/10.3109/00365529209000073.

129. Zuhl M, Schneider S, Lanphere K, Conn C, Dokladny K, Moseley P. Exercise regulation of intestinal tight junction proteins. Br J Sports Med. 2014;48(12): 980-6. https://doi.org/10.1136/bjsports-2012-091585.

130. Brock-Utne JG, Gaffin SL, Wells MT, Gathiram P, Sohar E, James MF, et al. Endotoxaemia in exhausted runners after a long-distance race. S Afr Med J. 1988;73(9):533-6.

131. Luo B, Xiang D, Nieman DC, Chen P. The effects of moderate exercise on chronic stress-induced intestinal barrier dysfunction and antimicrobial defense. Brain Behav Immun. 2014;39:99-106 https://doi.org/10.1016/j.bbi. 2013.11.013

132. Johannesson E, Simren M, Strid H, Bajor A, Sadik R. Physical activity improves symptoms in irritable bowel syndrome: a randomized controlled trial. Am J Gastroenterol. 2011;106(5):915-22 https://doi.org/10.1038/ajg. 2010.480.

133. Cronin O, O'Sullivan O, Barton W, Cotter PD, Molloy MG, Shanahan F. Gut microbiota: implications for sports and exercise medicine. Br J Sports Med. 2017;51(9):700-1. https://doi.org/10.1136/bjsports-2016-097225.

134. David LA, Maurice CF, Carmody RN, Gootenberg DB, Button JE, Wolfe BE, et al. Diet rapidly and reproducibly alters the human gut microbiome. Nature. 2014:505(7484):559-63 https://doi.org/10.1038/nature12820.

135. Falony G, Joossens M, Vieira-Silva S, Wang J, Darzi Y, Faust K, et al. Population-level analysis of gut microbiome variation. Science. 2016; 352(6285):560-4 https://doi.org/10.1126/science.aad3503.

136. Zhernakova A, Kurilshikov A, Bonder MJ, Tigchelaar EF, Schirmer M, Vatanen $T$, et al. Population-based metagenomics analysis reveals markers for gut microbiome composition and diversity. Science. 2016;352(6285):565-9 https://doi.org/10.1126/science.aad3369.

137. Portune K, Beaumont M, Davila A, Tome D, Blachier F, Sanz Y. Gut microbiota role in dietary protein metabolism and health-related outcomes: the two sides of the coin. Trends Food Sci Technol. 2016;57:213-32 https:// doi.org/10.1016/j.tifs.2016.08.011.

138. Rowland I, Gibson G, Heinken A, Scott K, Swann J, Thiele I, et al. Gut microbiota functions: metabolism of nutrients and other food components. Eur J Nutr. 2018:57(1):1-24 https://doi.org/10.1007/s00394-017-1445-8.

139. Neis EP, Dejong $\mathrm{CH}$, Rensen SS. The role of microbial amino acid metabolism in host metabolism. Nutrients. 2015;7(4):2930-46 https://doi. org/10.3390/nu7042930

140. Kerksick CM, Wilborn CD, Roberts MD, Smith-Ryan A, Kleiner SM, Jager R, et al. ISSN exercise \& sports nutrition review update: research \& recommendations. J Int Soc Sports Nutr. 2018;15(1):38 https://doi.org/10. 1186/s12970-018-0242-y. 
141. Tiller NB, Roberts JD, Beasley L, Chapman S, Pinto JM, Smith L, et al. International Society of Sports Nutrition Position Stand: nutritional considerations for single-stage ultra-marathon training and racing. J Int Soc Sports Nutr. 2019;16(1):50 https://doi.org/10.1186/s12970-019-0312-9.

142. Krajmalnik-Brown R, llhan ZE, Kang DW, DiBaise JK. Effects of gut microbes on nutrient absorption and energy regulation. Nutr Clin Pract. 2012;27(2): 201-14 https://doi.org/10.1177/0884533611436116.

143. Bergman EN. Energy contributions of volatile fatty acids from the gastrointestinal tract in various species. Physiol Rev. 1990;70(2):567-90 https://doi.org/10.1152/physrev.1990.70.2.567.

144. Parker DS. The measurement of production rates of volatile fatty acids in the caecum of the conscious rabbit. Br J Nutr. 1976;36(1):61-70 https://doi. org/10.1079/bjn19760058.

145. Rosenbaum M, Knight $R$, Leibel RL. The gut microbiota in human energy homeostasis and obesity. Trends Endocrinol Metab. 2015;26(9):493-501 https://doi.org/10.1016/j.tem.2015.07.002.

146. Heiss CN, Olofsson LE. Gut microbiota-dependent modulation of energy metabolism. J Innate Immun. 2018;10(3):163-71 https://doi.org/10.1159/ 000481519.

147. Donia MS, Fischbach MA. Small molecules from the human microbiota. Science. 2015;349(6246):1254766 https://doi.org/10.1126/science.1254766.

148. Riedl RA, Atkinson SN, Burnett CML, Grobe JL, Kirby JR. The gut microbiome, energy homeostasis, and implications for hypertension. Curr Hypertens Rep. 2017;19(4):27 https://doi.org/10.1007/s11906-017-0721-6.

149. Avolio E, Gualtieri P, Romano L, Pecorella C, Ferraro S, Di Renzo L, et al. Obesity and body composition in man and woman: associated diseases and new role of gut microbiota. Curr Med Chem. 2019;27(2):216-29 https:// doi.org/10.2174/0929867326666190326113607.

150. Tagliabue A, Elli M. The role of gut microbiota in human obesity: recent findings and future perspectives. Nutr Metab Cardiovasc Dis. 2013;23(3):1608 https://doi.org/10.1016/j.numecd.2012.09.002.

151. Scheithauer TP, Dallinga-Thie GM, de Vos WM, Nieuwdorp M, van Raalte DH. Causality of small and large intestinal microbiota in weight regulation and insulin resistance. Mol Metab. 2016;5(9):759-70 https://doi.org/10.1016/j. molmet.2016.06.002.

152. Turnbaugh PJ, Ley RE, Mahowald MA, Magrini V, Mardis ER, Gordon JI. An obesity-associated gut microbiome with increased capacity for energy harvest. Nature. 2006;444(7122):1027-31 https://doi.org/10.1038/ nature05414.

153. Backhed F, Ding H, Wang T, Hooper LV, Koh GY, Nagy A, et al. The gut microbiota as an environmental factor that regulates fat storage. Proc Nat Acad Sci U S A. 2004;101(44):15718-23 https://doi.org/10.1073/pnas. 0407076101.

154. Vaughn AC, Cooper EM, DiLorenzo PM, O'Loughlin LJ, Konkel ME, Peters JH, et al. Energy-dense diet triggers changes in gut microbiota, reorganization of gutbrain vagal communication and increases body fat accumulation. Acta Neurobiol Exp. 2017;77(1):18-30 https://doi.org/10.21307/ane-2017-033.

155. Turnbaugh PJ, Hamady M, Yatsunenko T, Cantarel BL, Duncan A, Ley RE, et al. A core gut microbiome in obese and lean twins. Nature. 2009; 457(7228):480-4 https://doi.org/10.1038/nature07540.

156. Cotillard A, Kennedy SP, Kong LC, Prifti E, Pons N, Le Chatelier E, et al. Dietary intervention impact on gut microbial gene richness. Nature. 2013; 500(7464):585-8 https://doi.org/10.1038/nature12480.

157. Jumpertz R, Le DS, Turnbaugh PJ, Trinidad C, Bogardus C, Gordon Il, et al. Energy-balance studies reveal associations between gut microbes, caloric load, and nutrient absorption in humans. Am J Clin Nutr. 2011;94(1):58-65 https://doi.org/10.3945/ajcn.110.010132.

158. Mountjoy M, Sundgot-Borgen J, Burke L, Carter S, Constantini N, Lebrun C, et al. The IOC consensus statement: beyond the female athlete triad-relative energy deficiency in sport (RED-S). Br J Sports Med. 2014;48(7):491-7 https://doi.org/10.1136/bjsports-2014-093502.

159. Zheng $X$, Wang $S$, Jia W. Calorie restriction and its impact on gut microbial composition and global metabolism. Front Med. 2018;12(6):634-44 https:// doi.org/10.1007/s11684-018-0670-8.

160. Tanca A, Abbondio M, Palomba A, Fraumene C, Marongiu F, Serra M, et al. Caloric restriction promotes functional changes involving short-chain fatty acid biosynthesis in the rat gut microbiota. Sci Rep. 2018;8(1):14778 https:// doi.org/10.1038/s41598-018-33100-y.

161. Aron-Wisnewsky J, Dore J, Clement K. The importance of the gut microbiota after bariatric surgery. Nat Rev Gastroenterol Hepatol. 2012;9(10):590-8 https://doi.org/10.1038/nrgastro.2012.161.
162. Rejeh N, Ahmadi F, Mohammadi E, Anoosheh M, Kazemnejad A. Barriers to, and facilitators of post-operative pain management in Iranian nursing: a qualitative research study. Int Nurs Rev. 2008;55(4):468-75 https://doi.org/10. 1111/j.1466-7657.2008.00659.x.

163. Furet JP, Kong LC, Tap J, Poitou C, Basdevant A, Bouillot JL, et al. Differential adaptation of human gut microbiota to bariatric surgery-induced weight loss: links with metabolic and low-grade inflammation markers. Diabetes. 2010;59(12):3049-57 https://doi.org/10.2337/db10-0253.

164. Blanton LV, Charbonneau MR, Salih T, Barratt MJ, Venkatesh S, Ilkaveya O, et al. Gut bacteria that prevent growth impairments transmitted by microbiota from malnourished children. Science. 2016;351(6275) https://doi. org/10.1126/science.aad3311.

165. Subramanian S, Huq S, Yatsunenko T, Haque R, Mahfuz M, Alam MA, et al. Persistent gut microbiota immaturity in malnourished Bangladeshi children. Nature. 2014:510(7505):417-21 https://doi.org/10.1038/nature13421.

166. Charbonneau MR, O'Donnell D, Blanton LV, Totten SM, Davis JC, Barratt MJ, et al. Sialylated Milk oligosaccharides promote microbiota-dependent growth in models of infant undernutrition. Cell. 2016;164(5):859-71 https:// doi.org/10.1016/j.cell.2016.01.024.

167. Mack I, Penders J, Cook J, Dugmore J, Mazurak N, Enck P. Is the impact of starvation on the gut microbiota specific or unspecific to anorexia nervosa? A narrative review based on a systematic literature search. Curr Neuropharmacol. 2018;16(8):1131-49 https://doi.org/10.2174/ $1570159 \times 16666180118101354$.

168. Borgo F, Riva A, Benetti A, Casiraghi MC, Bertelli S, Garbossa S, et al. Microbiota in anorexia nervosa: the triangle between bacterial species, metabolites and psychological tests. PLoS One. 2017;12(6):e0179739 https:// doi.org/10.1371/journal.pone.0179739.

169. Mack I, Cuntz U, Gramer C, Niedermaier S, Pohl C, Schwiertz A, et al. Weight gain in anorexia nervosa does not ameliorate the faecal microbiota, branched chain fatty acid profiles, and gastrointestinal complaints. Sci Rep. 2016;6:26752 https://doi.org/10.1038/srep26752.

170. Kleiman SC, Watson HJ, Bulik-Sullivan EC, Huh EY, Tarantino LM, Bulik CM, et al. The intestinal microbiota in acute anorexia nervosa and during Renourishment: relationship to depression, anxiety, and eating disorder psychopathology. Psychosom Med. 2015;77(9):969-81 https://doi.org/10. 1097/PSY.0000000000000247.

171. Sheflin AM, Melby CL, Carbonero F, Weir TL. Linking dietary patterns with gut microbial composition and function. Gut Microbes. 2017;8(2):113-29 https://doi.org/10.1080/19490976.2016.1270809.

172. Wu GD, Chen J, Hoffmann C, Bittinger K, Chen YY, Keilbaugh SA, et al. Linking long-term dietary patterns with gut microbial enterotypes. Science. 2011;334(6052):105-8 https://doi.org/10.1126/science.1208344.

173. Brinkworth GD, Noakes M, Clifton PM, Bird AR. Comparative effects of very low-carbohydrate, high-fat and high-carbohydrate, low-fat weight-loss diets on bowel habit and faecal short-chain fatty acids and bacterial populations. Br J Nutr. 2009;101(10):1493-502 https://doi.org/10.1017/ S0007114508094658

174. Duncan SH, Belenguer A, Holtrop G, Johnstone AM, Flint HJ, Lobley GE. Reduced dietary intake of carbohydrates by obese subjects results in decreased concentrations of butyrate and butyrate-producing bacteria in feces. Appl Environ Microbiol. 2007;73(4):1073-8 https://doi.org/10.1128/ AEM.02340-06.

175. Russell WR, Gratz SW, Duncan SH, Holtrop G, Ince J, Scobbie L, et al. Highprotein, reduced-carbohydrate weight-loss diets promote metabolite profiles likely to be detrimental to colonic health. Am J Clin Nutr. 2011;93(5): 1062-72 https://doi.org/10.3945/ajcn.110.002188.

176. Magee EA, Richardson CJ, Hughes R, Cummings JH. Contribution of dietary protein to sulfide production in the large intestine: an in vitro and a controlled feeding study in humans. Am J Clin Nutr. 2000;72(6):1488-94 https://doi.org/10.1093/ajcn/72.6.1488.

177. Rowan FE, Docherty NG, Coffey JC, O'Connell PR. Sulphate-reducing bacteria and hydrogen sulphide in the aetiology of ulcerative colitis. $\mathrm{Br} \mathrm{J}$ Surg. 2009;96(2):151-8 https://doi.org/10.1002/bjs.6454.

178. Ma N, Tian Y, Wu Y, Ma X. Contributions of the interaction between dietary protein and gut microbiota to intestinal health. Curr Protein Pept Sci. 2017; 18(8):795-808 https://doi.org/10.2174/1389203718666170216153505.

179. Arumugam M, Raes J, Pelletier E, Le Paslier D, Yamada T, Mende DR, et al. Enterotypes of the human gut microbiome. Nature. 2011;473(7346):174-80 https://doi.org/10.1038/nature09944. 
180. Costea PI, Hildebrand F, Arumugam M, Backhed F, Blaser MJ, Bushman FD, et al. Enterotypes in the landscape of gut microbial community composition. Nat Microbiol. 2018;3(1):8-16 https://doi.org/10.1038/s41564017-0072-8.

181. Knights D, Ward TL, McKinlay CE, Miller H, Gonzalez A, McDonald D, et al. Rethinking "enterotypes". Cell Host Microbe. 2014;16(4):433-7 https://doi. org/10.1016/j.chom.2014.09.013.

182. Macfarlane GT, Macfarlane S. Bacteria, colonic fermentation, and gastrointestinal health. J AOAC Int. 2012;95(1):50-60 https://doi.org/10.5740/ jaoacint.sge_macfarlane.

183. Rist VT, Weiss E, Eklund M, Mosenthin R. Impact of dietary protein on microbiota composition and activity in the gastrointestinal tract of piglets in relation to gut health: a review. Animal. 2013;7(7):1067-78 https://doi.org/ 10.1017/S1751731113000062.

184. McAllan L, Skuse P, Cotter PD, O'Connor P, Cryan JF, Ross RP, et al. Protein quality and the protein to carbohydrate ratio within a high fat diet influences energy balance and the gut microbiota in C57BL/6J mice. PLoS One. 2014;9(2):e88904 https://doi.org/10.1371/journal.pone.0088904.

185. Tranberg B, Hellgren LI, Lykkesfeldt J, Sejrsen K, Jeamet A, Rune I, et al. Whey protein reduces early life weight gain in mice fed a high-fat diet. PLoS One. 2013;8(8):e71439 https://doi.org/10.1371/journal.pone.0071439.

186. Belobrajdic DP, Mclntosh GH, Owens JA. A high-whey-protein diet reduces body weight gain and alters insulin sensitivity relative to red meat in wistar rats. J Nutr. 2004;134(6):1454-8 https://doi.org/10.1093/jn/134.6.1454.

187. Tipton KD, Wolfe RR. Protein and amino acids for athletes. J Sports Sci. 2004; 22(1):65-79 https://doi.org/10.1080/0264041031000140554.

188. Jalanka-Tuovinen J, Salonen A, Nikkila J, Immonen O, Kekkonen R, Lahti L, et al. Intestinal microbiota in healthy adults: temporal analysis reveals individual and common core and relation to intestinal symptoms. PLoS One. 2011;6(7):e23035 https://doi.org/10.1371/journal.pone.0023035.

189. Frank DN, St Amand AL, Feldman RA, Boedeker EC, Harpaz N, Pace NR. Molecular-phylogenetic characterization of microbial community imbalances in human inflammatory bowel diseases. Proc Natl Acad Sci U S A. 2007;104(34):13780-5 https://doi.org/10.1073/pnas.0706625104.

190. Fujimoto T, Imaeda H, Takahashi K, Kasumi E, Bamba S, Fujiyama Y, et al. Decreased abundance of Faecalibacterium prausnitzii in the gut microbiota of Crohn's disease. J Gastroenterol Hepatol. 2013;28(4):613-9 https://doi.org/ 10.1111/jgh.12073.

191. Holmes E, Li JV, Athanasiou T, Ashrafian H, Nicholson JK. Understanding the role of gut microbiome-host metabolic signal disruption in health and disease. Trends Microbiol. 2011;19(7):349-59 https://doi.org/10.1016/j.tim. 2011.05.006

192. Negro M, Giardina S, Marzani B, Marzatico F. Branched-chain amino acid supplementation does not enhance athletic performance but affects muscle recovery and the immune system. J Sports Med Phys Fitness. 2008;48(3): 347-51.

193. van Hall G, Raaymakers JS, Saris WH, Wagenmakers AJ. Ingestion of branched-chain amino acids and tryptophan during sustained exercise in man: failure to affect performance. J Physiol. 1995;486(Pt 3):789-94 https:// doi.org/10.1113/jphysiol.1995.sp020854.

194. Newsholme EA, Blomstrand E. Branched-chain amino acids and central fatigue J Nutr. 2006;136(1 Suppl):274S-6S https://doi.org/10.1093/jn/136.1.274S.

195. Greer BK, Woodard JL, White JP, Arguello EM, Haymes EM. Branched-chain amino acid supplementation and indicators of muscle damage after endurance exercise. Int J Sport Nutr Exerc Metab. 2007;17(6):595-607 https://doi.org/10.1123/ijsnem.17.6.595.

196. Moreno-Perez D, Bressa C, Bailen M, Hamed-Bousdar S, Naclerio F, Carmona $M$, et al. Effect of a protein supplement on the gut microbiota of endurance athletes: a randomized, controlled. Double-Blind Pilot Study Nutrients. 2018; 10(3):337 https://doi.org/10.3390/nu10030337.

197. Williams BA, Zhang D, Lisle AT, Mikkelsen D, McSweeney CS, Kang S, et al. Soluble arabinoxylan enhances large intestinal microbial health biomarkers in pigs fed a red meat-containing diet. Nutrition. 2016;32(4):491-7 https:// doi.org/10.1016/j.nut.2015.10.008

198. Jager R, Shields KA, Lowery RP, De Souza EO, Partl JM, Hollmer C, et al. Probiotic Bacillus coagulans GBI-30, 6086 reduces exercise-induced muscle damage and increases recovery. PeerJ. 2016;4:e2276 https://doi.org/10.7717/ peerj.2276.

199. Cronin O, Barton W, Skuse P, Penney NC, Garcia-Perez I, Murphy EF, et al. A Prospective Metagenomic and Metabolomic Analysis of the Impact of Exercise and/or Whey Protein Supplementation on the Gut Microbiome of
Sedentary Adults. mSystems. 2018;3(3) https://doi.org/10.1128/mSystems. 00044-18.

200. Mukhopadhya I, Segal JP, Carding SR, Hart AL, Hold GL. The gut virome: the 'missing link' between gut bacteria and host immunity? Ther Adv Gastroenterol. 2019;12:1756284819836620 https://doi.org/10.1177/ 1756284819836620.

201. Butteiger DN, Hibberd AA, McGraw NJ, Napawan N, Hall-Porter JM, Krul ES. Soy protein compared with Milk protein in a Western diet increases gut microbial diversity and reduces serum lipids in Golden Syrian hamsters. J Nutr. 2016;146(4):697-705 https://doi.org/10.3945/jn.115.224196.

202. Gentile CL, Ward E, Holst JJ, Astrup A, Ormsbee MJ, Connelly S, et al. Resistant starch and protein intake enhances fat oxidation and feelings of fullness in lean and overweight/obese women. Nutr J. 2015;14:113 https:// doi.org/10.1186/s12937-015-0104-2.

203. Martens EC. Microbiome: fibre for the future. Nature. 2016;529(7585):158-9 https://doi.org/10.1038/529158a.

204. El Kaoutari A, Armougom F, Gordon Jl, Raoult D, Henrissat B. The abundance and variety of carbohydrate-active enzymes in the human gut microbiota. Nat Rev Microbiol. 2013;11(7):497-504 https://doi.org/10.1038/ nrmicro3050.

205. Simpson HL, Campbell BJ. Review article: dietary fibre-microbiota interactions. Aliment Pharmacol Ther. 2015;42(2):158-79 https://doi.org/10. 1111/apt.13248

206. Tap J, Furet JP, Bensaada M, Philippe C, Roth H, Rabot S, et al. Gut microbiota richness promotes its stability upon increased dietary fibre intake in healthy adults. Environ Microbiol. 2015;17(12):4954-64 https://doi org/10.1111/1462-2920.13006.

207. O'Keefe SJ, Li JV, Lahti L, Ou J, Carbonero F, Mohammed K, et al. Fat, fibre and cancer risk in African Americans and rural Africans. Nat Commun. 2015; 6:6342 https://doi.org/10.1038/ncomms7342

208. Cramp T, Broad E, Martin D, Meyer BJ. Effects of preexercise carbohydrate ingestion on mountain bike performance. Med Sci Sports Exerc. 2004;36(9): 1602-9 https://doi.org/10.1249/01.mss.0000139805.91675.5b.

209. Jacobs KA, Sherman WM. The efficacy of carbohydrate supplementation and chronic high- carbohydrate diets for improving endurance performance. Int J Sport Nutr. 1999:9(1):92-115 https://doi.org/10.1123/ijsn.9.1.92.

210. Gorvitovskaia A, Holmes SP, Huse SM. Interpreting Prevotella and Bacteroides as biomarkers of diet and lifestyle. Microbiome. 2016:4:15 https://doi.org/10.1186/s40168-016-0160-7.

211. Lim MY, Rho M, Song YM, Lee K, Sung J, Ko G. Stability of gut enterotypes in Korean monozygotic twins and their association with biomarkers and diet. Sci Rep. 2014;4:7348 https://doi.org/10.1038/srep07348.

212. Nakayama J, Watanabe K, Jiang J, Matsuda K, Chao SH, Haryono P, et al. Diversity in gut bacterial community of school-age children in Asia. Sci Rep. 2015;5:8397 https://doi.org/10.1038/srep08397.

213. De Filippo C, Cavalieri D, Di Paola M, Ramazzotti M, Poullet JB, Massart S, et al. Impact of diet in shaping gut microbiota revealed by a comparative study in children from Europe and rural Africa. Proc Natl Acad Sci U S A. 2010;107(33):14691-6 https://doi.org/10.1073/pnas.1005963107.

214. Liu Y, Zhang L, Wang X, Wang Z, Zhang J, Jiang R, et al. Similar fecal microbiota signatures in patients with diarrhea-predominant irritable bowel syndrome and patients with depression. Clin Gastroenterol Hepatol. 2016; 14(11):1602-11.e5 https://doi.org/10.1016/j.cgh.2016.05.033.

215. Moreno-Indias I, Sanchez-Alcoholado L, Garcia-Fuentes E, Cardona F, Queipo-Ortuno MI, Tinahones FJ. Insulin resistance is associated with specific gut microbiota in appendix samples from morbidly obese patients. Am J Transl Res. 2016;8(12):5672-84.

216. Michail S, Lin M, Frey MR, Fanter R, Paliy O, Hilbush B, et al. Altered gut microbial energy and metabolism in children with non-alcoholic fatty liver disease. FEMS Microbiol Ecol. 2015;91(2):1-9 https://doi.org/10.1093/femsec/ fiu002.

217. Li J, Zhao F, Wang Y, Chen J, Tao J, Tian G, et al. Gut microbiota dysbiosis contributes to the development of hypertension. Microbiome. 2017;5(1):14 https://doi.org/10.1186/s40168-016-0222-x

218. Chen W, Liu F, Ling Z, Tong $X$, Xiang C. Human intestinal lumen and mucosa-associated microbiota in patients with colorectal cancer. PLoS One. 2012;7(6):e39743 https://doi.org/10.1371/journal.pone.0039743.

219. Precup G, Vodnar DC. Gut Prevotella as a possible biomarker of diet and its eubiotic versus dysbiotic roles: a comprehensive literature review. $\mathrm{Br} J$ Nutr. 2019:122(2):131-40 https://doi.org/10.1017/S0007114519000680. 
220. Thomas DT, Erdman KA, Burke LM. American College of Sports Medicine joint position statement. Nutrition and athletic performance. Med Sci Sports Exerc. 2016;48(3):543-68 https://doi.org/10.1249/MSS.0000000000000852.

221. Jeukendrup AE. Training the gut for athletes. Sports Med. 2017;47(Suppl 1): 101-10 https://doi.org/10.1007/s40279-017-0690-6.

222. Toden S, Bird AR, Topping DL, Conlon MA. Resistant starch prevents colonic DNA damage induced by high dietary cooked red meat or casein in rats. Cancer Biol Ther. 2006;5(3):267-72 https://doi.org/10.4161/cbt.5.3.2382

223. Samuel BS, Hansen EE, Manchester JK, Coutinho PM, Henrissat B, Fulton R, et al. Genomic and metabolic adaptations of Methanobrevibacter smithii to the human gut. Proc Natl Acad Sci U S A. 2007;104(25):10643-8 https://doi. org/10.1073/pnas.0704189104.

224. Canfora EE, Jocken JW, Blaak EE. Short-chain fatty acids in control of body weight and insulin sensitivity. Nat Rev Endocrinol. 2015;11(10):577-91 https://doi.org/10.1038/nrendo.2015.128.

225. Roelofsen H, Priebe MG, Vonk RJ. The interaction of short-chain fatty acids with adipose tissue: relevance for prevention of type 2 diabetes. Benefic Microbes. 2010;1(4):433-7 https://doi.org/10.3920/BM2010.0028.

226. Kaji I, Karaki S, Kuwahara A. Short-chain fatty acid receptor and its contribution to glucagon-like peptide-1 release. Digestion. 2014;89(1):31-6 https://doi.org/10.1159/000356211.

227. Astbury SM, Corfe BM. Uptake and metabolism of the short-chain fatty acid butyrate, a critical review of the literature. Curr Drug Metab. 2012;13(6):81521 https://doi.org/10.2174/138920012800840428.

228. den Besten G, Bleeker A, Gerding A, van Eunen $K$, Havinga R, van Dijk TH, et al. Short-chain fatty acids protect against high-fat diet-induced obesity via a PPARgamma-dependent switch from lipogenesis to fat oxidation. Diabetes. 2015;64(7):2398-408 https://doi.org/10.2337/db14-1213.

229. Caesar R, Tremaroli V, Kovatcheva-Datchary P, Cani PD, Backhed F. Crosstalk between gut microbiota and dietary lipids aggravates WAT inflammation through TLR signaling. Cell Metab. 2015;22(4):658-68 https://doi.org/10. 1016/j.cmet.2015.07.026.

230. Murtaza N, Burke LM, Vlahovich N, Charlesson B, H ON, Ross ML, et al. The Effects of Dietary Pattern during Intensified Training on Stool Microbiota of Elite Race Walkers. Nutrients. 2019;11(2) https://doi.org/10.3390/nu11020261.

231. Sokol H, Pigneur B, Watterlot L, Lakhdari O, Bermudez-Humaran LG, Gratadoux JJ, et al. Faecalibacterium prausnitzii is an anti-inflammatory commensal bacterium identified by gut microbiota analysis of Crohn disease patients. Proc Natl Acad Sci U S A. 2008;105(43):16731-6 https://doi. org/10.1073/pnas.0804812105.

232. Fiorucci S, Distrutti E. Bile acid-activated receptors, intestinal microbiota, and the treatment of metabolic disorders. Trends Mol Med. 2015;21(11):702-14 https://doi.org/10.1016/j.molmed.2015.09.001.

233. Lopez-Siles M, Khan TM, Duncan SH, Harmsen HJ, Garcia-Gil LJ, Flint HJ. Cultured representatives of two major phylogroups of human colonic Faecalibacterium prausnitzii can utilize pectin, uronic acids, and hostderived substrates for growth. Appl Environ Microbiol. 2012;78(2):420-8 https://doi.org/10.1128/AEM.06858-11.

234. Burke LM, Hawley JA, Jeukendrup A, Morton JP, Stellingwerff T, Maughan RJ. Toward a common understanding of diet-exercise strategies to manipulate fuel availability for training and competition preparation in endurance sport. Int J Sport Nutr Exerc Metab. 2018;28(5):451-63 https://doi.org/10.1123/ ijsnem.2018-0289.

235. Kozich JJ, Westcott SL, Baxter NT, Highlander SK, Schloss PD. Development of a dual-index sequencing strategy and curation pipeline for analyzing amplicon sequence data on the MiSeq Illumina sequencing platform. Appl Environ Microbiol. 2013;79(17):5112-20 https://doi.org/10.1128/AEM.01043-13.

236. Revicki DA, Wood M, Wiklund I, Crawley J. Reliability and validity of the gastrointestinal symptom rating scale in patients with gastroesophageal reflux disease. Qual Life Res. 1998;7(1):75-83 https://doi.org/10.1023/a: 1008841022998.

237. Blake MR, Raker JM, Whelan K. Validity and reliability of the Bristol stool form scale in healthy adults and patients with diarrhoea-predominant irritable bowel syndrome. Aliment Pharmacol Ther. 2016;44(7):693-703 https://doi.org/10.1111/apt.13746.

238. Cardona S, Eck A, Cassellas M, Gallart M, Alastrue C, Dore J, et al. Storage conditions of intestinal microbiota matter in metagenomic analysis. BMC Microbiol. 2012;12:158 https://doi.org/10.1186/1471-2180-12-158.

239. Roesch LF, Casella G, Simell O, Krischer J, Wasserfall CH, Schatz D, et al. Influence of fecal sample storage on bacterial community diversity. Open Microbiol J. 2009:3:40-6 https://doi.org/10.2174/1874285800903010040.
240. Li F, Hullar MA, Lampe JW. Optimization of terminal restriction fragment polymorphism (TRFLP) analysis of human gut microbiota. J Microbiol Methods. 2007;68(2):303-11 https://doi.org/10.1016/j.mimet.2006.09.006.

241. Debelius J, Song SJ, Vazquez-Baeza Y, Xu ZZ, Gonzalez A, Knight R. Tiny microbes, enormous impacts: what matters in gut microbiome studies? Genome Biol. 2016;17(1):217 https://doi.org/10.1186/s13059-016-1086-X.

242. Liang Y, Dong T, Chen M, He L, Wang T, Liu X, et al. Systematic Analysis of Impact of Sampling Regions and Storage Methods on Fecal Gut Microbiome and Metabolome Profiles. mSphere. 2020;5(1) https://doi.org/ 10.1128/mSphere.00763-19.

\section{Publisher's Note}

Springer Nature remains neutral with regard to jurisdictional claims in published maps and institutional affiliations.
Ready to submit your research? Choose BMC and benefit from:

- fast, convenient online submission

- thorough peer review by experienced researchers in your field

- rapid publication on acceptance

- support for research data, including large and complex data types

- gold Open Access which fosters wider collaboration and increased citations

- maximum visibility for your research: over $100 \mathrm{M}$ website views per year

At BMC, research is always in progress.

Learn more biomedcentral.com/submissions 